\title{
Fast processing and continuous simulation of automotive structural composite components
}

\author{
Frank Henning ${ }^{\mathrm{a}, \mathrm{b}, *}$, Luise Kärger ${ }^{\mathrm{a}}$, Dominik Dörr ${ }^{\mathrm{a}}$, Fabian J. Schirmaier ${ }^{\mathrm{a}}$, Julian Seuffert ${ }^{\mathrm{a}}$, \\ Alexander Bernath ${ }^{\mathrm{a}}$ \\ ${ }^{\mathrm{a}}$ Karlsruhe Institute of Technology (KIT), Institute of Vehicle System Technology (FAST), Lightweight Technology, Karlsruhe, Germany \\ ${ }^{\mathrm{b}}$ Fraunhofer Institute for Chemical Technology (ICT), Pfinztal, Germany
}

\author{
A B S T R A C T
}

Keywords:

Automotive composites

RTM

Tape

Forming

Molding

Injection

Curing

Process simulation

Process chain

CAE chain
Due to application-specific tailoring, continuous fiber reinforced plastics (CoFRP) provide an exceptional lightweight potential and are particularly suited for structural components. The use of CoFRP specifically for weight reduction of the automotive car body is the major focus of this feature article. Automotive mass production requires fast and qualified, thus highly automated and material efficient manufacturing technologies. Consequently, CoFRP manufacturing for automotive differs considerably from conventional CoFRP manufacturing for aerospace, particularly in terms of higher throughput with higher investment, but lower operating effort. Furthermore, automotive structures have smaller dimensions with more complex shapes, which makes it more challenging to avoid forming defects and to ensure complete injection. Since manufacturing makes the main difference between automotive and aerospace composite components, this feature article puts emphasis on the process technologies and on the corresponding material behavior and process simulation methods. For a holistic product design of automotive CoFRP components, a simultaneous virtual description and virtual optimization of both manufacturing process and structural capacity is necessary. Production effects must be considered in the part design and, thus, must be reliably predicted by process simulation as well as taken into account in subsequent simulation steps. This feature article therefore evaluates the current state of the art in the continuous virtual representation of CoFRP process chains, including the process steps forming, injection and curing. Furthermore, the integrated optimization along this CAE chain is a key factor for an economic part design and therefore another major subject of this article.

\section{Introduction}

Lightweighting is the holistic implementation of a development strategy that aims to realize the required function under specified technical, economic, environmental and social constraints by a system of minimum mass while ensuring system reliability. Lightweighting means increasing a system's efficiency rather than just reducing the weight of the system. It therefore requires a system approach with defined boundary conditions. To achieve this comprehensive goal, the authors pursue an engineering approach, in which science contributes to the development of methods, materials and production technologies, called MMP approach according to Henning and Möller [1]. In this consequence, this feature article takes an integrated look at process technologies, material behavior and process simulation chains.

This article is focusing specifically on the automotive industry and on the use of high performance structural composites for weight reduction of the car body. Composite materials provide a particularly high lightweight potential and have the advantage to be tailor made to the application. While the aerospace industry has been using high performance materials such as carbon fiber reinforced composites for decades, the automotive sector traditionally and still uses mainly commodity materials such as steel, aluminum and short glass fiber re inforced composites [2]. This is owed to the automotive mass manu facturing in which materials are cost drivers due to the high throughput. Not only the material itself, also the design and the man ufacturing technologies need a completely different approach [2]. Au tomotive requires highly automated and robust production technolo gies, which can be quite expensive in terms of investment [3]. However, due to the high throughput, the production will still be economically feasible as long as the material costs are affordable. The opposite ap plies to aerospace, where low cost tooling is in focus due to a limited number of components to be produced. Consequently, semi automated

\footnotetext{
* Corresponding author. Karlsruhe Institute of Technology (KIT), Institute of Vehicle System Technology (FAST), Lightweight Technology, Karlsruhe, Germany.

E-mail addresses: frank.henning@kit.edu, frank.henning@ict.fraunhofer.de (F. Henning).
} 


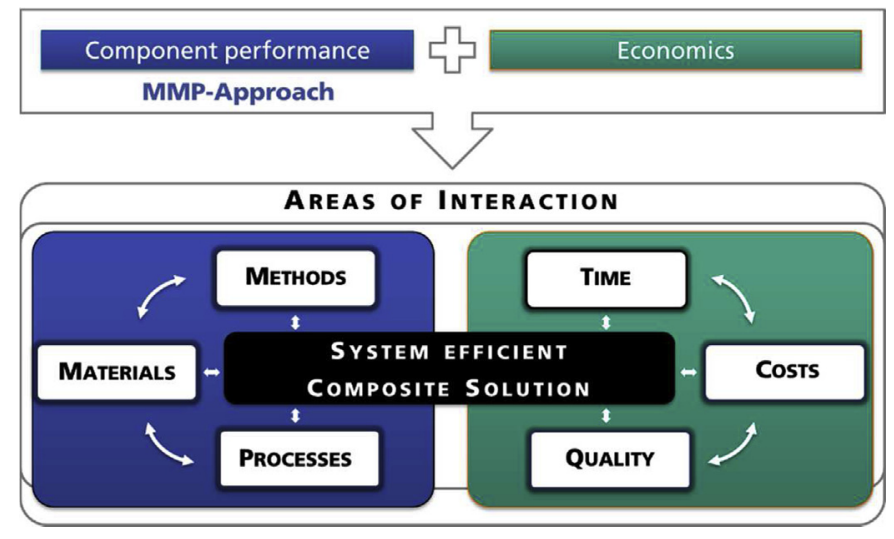

Fig. 1. Areas of interaction to find a system efficient composite solution.

processes with much more manual labor are applied. For automotive applications it is therefore more crucial than for aerospace applications that system efficient composite solutions are developed, which consider not only technical and technological targets, but also the economical boundary conditions, cf. Fig. 1 . Due to the increasing political demand for $\mathrm{CO}_{2}$ reduction, but also due to the global economic downturn and the rise in petroleum price in 2008, the automotive original equipment manufacturers (OEMs) have started to consider polymer composites in a new, more holistic way [4,5]. Manifold research studies have shown the application potential of structural composites for the automotive in dustry $[3,6]$. Nevertheless, too high production costs and limited un derstanding of automotive specific processes still hinder high perfor mance composites to enter the automotive mass production market. Therefore, one objective of this feature article is to examine the sci entific achievements so far and to discuss the open issues that need to be addressed in order to make the comparably small but more complex structural composites affordable for automotive applications.

Since high performance composites in particular are a major chal lenge for large scale production, the focus of this feature article is on structural composite components for automotive applications. Therefore, the following discussions will address continuous fiber re inforced plastics (CoFRP) only. Discontinuous fiber reinforced plastics (DicoFRP) are of course a very important subject for automotive lightweighting as well [5]. However, DicoFRP are applied mainly for semi structural or interior parts with complex shapes and with a focus on functional integration rather than load carrying structural capacity. These low cost composites are already established in the automotive industry for many years [3]. Particularly promising for cost efficient lightweighting is the combination of CoFRP and DiCoFRP to CoDi CoFRP, where the high performance CoFRP material is responsible for the structural performance in those areas required and the low cost DiCoFRP material enables complex geometries and increased functions $[7,8]$.

CoFRP manufacturing involves three main challenges which are particular important for the automotive industry. Firstly, processes hardly allow a production with cycle times of less than three minutes, as needed for automotive vehicle mass production. Resin Transfer Molding (RTM) and Wet Compression Molding (WCM) with fast curing polymers as well as thermoplastic organosheet or tape forming pro cesses provide such high productivity potential. Consequently, these processes are of highest interest for automotive composite applications and the main subject of this feature article. The second disadvantage of CoFRP manufacturing is the high cost of the involved raw materials. The costly material must, therefore, be used in an optimal manner to minimize the material consumption and avoid production waste [9]. The third challenge of CoFRP in automotive applications is the pro cessing of complex geometries at avoiding manufacturing defects like fiber wrinkling and gapping, incomplete filling or distortion.
Fully automized and thus reproducible composite processes are an important foundation for the development of reliable simulation tools [10]. In the field of method development, the automotive industry can partly benefit from the long standing experience in aerospace. How ever, new challenges are coming into play when cycle times must be reduced and adapted materials are employed. For example, the curing of highly reactive resins starts while the component is still being filled. Thus, increasing viscosities and increasing glass transmission tem peratures need be considered [11]. High flow velocities and high pressures cause higher demands on the modeling of air entrapments during injection, particularly at geometrical or material discontinuities [12]. When automotive and airplane structures are compared, another major difference is found in the complexity and size of components. Airplanes have larger structures with less complexity, while car struc tures have comparably small dimensions, very often with complex shapes. This makes it more challenging for forming simulation to pre dict reliably the resulting fiber structure and local forming defects [13].

To address these topics holistically, this feature paper is structured along the process chain and the correlated CAE chain, looking at both with interrelation. First, the relevant processes for automotive compo site part production are introduced in Section 2. Section 3 discusses the advantages of continuous simulation chains and their state of the art to predict and optimize the process and structural behavior of automotive composite parts. Subsequently, the single process and simulation steps of the continuous process chain are described in detail in Section 4, starting from the forming process (Section 4.1), over injection (Section 4.2), up to the evolution of residual stresses and distortions (Section 4.1). Finally, conclusions and future trends with emphasis on auto motive composites are drawn in Section 5.

\section{Rapid manufacturing of structural composite components for automotive applications}

\subsection{HP RTM with highly reactive thermoset resins}

Conventional Resin Transfer Molding (RTM) is a resin infusion process, which is established in industry for many decades. The process is suitable to manufacture structural applications mainly for the aero space industry as well as for niche applications such as luxury and sport cars with a limited number of total vehicles being produced. The con ventional RTM process is not suitable for the large scale production of automotive vehicles with considerable amount of composite compo nents such as the BMWi3 and i8 series. To establish structural compo site parts for large series, the process has to be further developed and modified in order to handle highly reactive resins, which enable short cycle times due to high automation, rapid filling and rapid curing. Compared to the conventional RTM technique, a special equipment is required, which allows an exact and rapid dosing under high pressure. Such equipment is able to handle a resin throughput of $20200 \mathrm{~g} / \mathrm{s}$. As a consequence, fast curing resins can be used, which cure in less than 3 min [14]. As conventional RTM, the High Pressure RTM (HP RTM) or Compression RTM (C RTM) can be separated in two main process steps: preforming and resin infiltration plus curing, see Fig. 2. The preforming step is independent of the chosen RTM variant. Due to comparably smaller and more complex parts in cars, the preforming is more chal lenging compared to airplanes.

\subsubsection{Preforming}

Manufacturing of continuously fiber reinforced parts requires the forming of an initially flat pre product into a three dimensional com ponent. During forming of complex shapes, pre products are subjected to large local and global deformations, which influence fiber orienta tion, fiber volume content and component thickness. Accompanied with possible defects like wrinkling and gapping, these effects influence the final part quality. For semi finished technical textiles without a resin and a continuous fiber architecture, forming into near net shape of the 


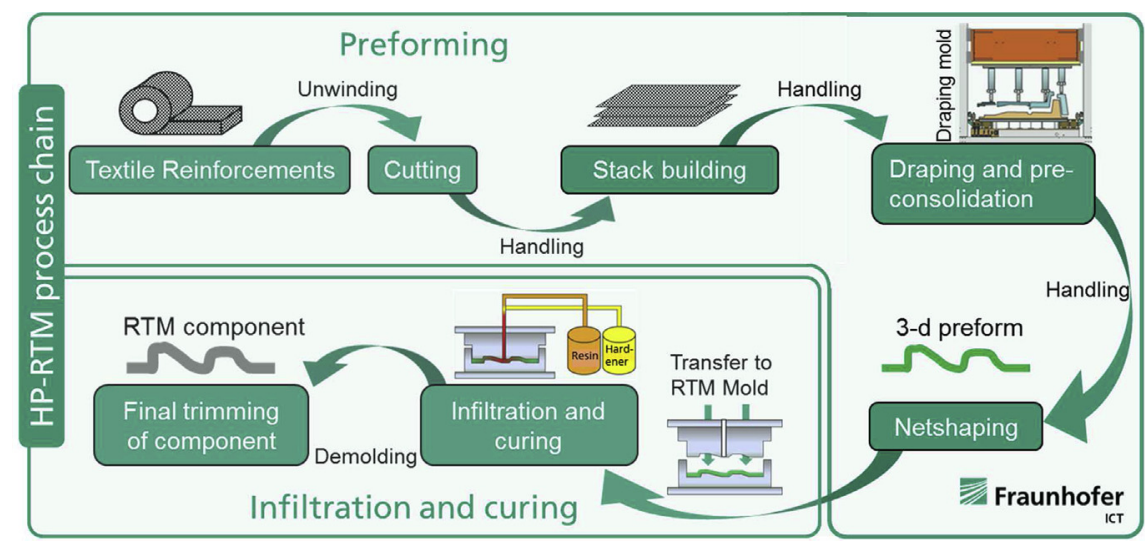

Fig. 2. HP-RTM process for manufacturing of complex CFRP components [Fraunhofer ICT].

component is called preforming.

Preforming processes can be subdivided in single and sequentially concurrent operations. Namely, these are the tailored cutting of the fabrics, the application of a binder on the cut single layers, the stacking of the fabrics and finally the draping and solidification of the binder. A binder system is utilized to guarantee dimensional stability for sub sequent handling of the formed semi finished part, called preform $[1,15,16]$. Possibly, the preform additionally needs to be trimmed prior to infiltration.

In preforming processes, continuous fiber architectures can be ei ther woven or stitch bonded. Woven fiber architectures are based on interlaced warp and weft yarns, according to a certain weave pattern, called bond type. For such woven fabrics, compromises are made on the structural performance of the composite due to the crimp of fiber bundles leading to fiber misalignments [17 19]. In contrast, non crimp fabrics (NCFs) combine crimp free unidirectional fiber layers by as sembling them by stitching and/or bonding by chemical agents [20].

Forming behavior of CoFRP can be significantly influenced by in ducing tensile forces, [21 23]. In this way, forming defects can be re duced or avoided. Several passive or active systems were developed to reduce those defects [24 28]. Friction based blank holders or grippers may reduce wrinkling behavior, but also may induce other forming defects like fiber displacements or fiber pull out. Therefore, Nezami et al. [15] presented in a recent study an approach for textile forming with piezo activated metal interlayers, which actively reduce friction between layers of a stacked laminate and thus reduce forming defects.

Experimental investigations of preform processes is still part of ongoing research, which includes the investigation of very local draping defects. This includes the investigation of intra ply tow sliding [29] or tow buckling $[25,30,31]$, where different origins and remedies are presented.

An alternative forming concept is the sequential forming process, which is based on the segmentation of the forming tool in several tools, to adapt the strike out of wrinkles of hand layup processes in a fully automatized process. Another approach for reducing forming defects is the segmentation of the formed fabric into so called sub preforms, which are assembled in a sequential preforming process to the final preform (cf. Fig. 3). In this manner, the formed fabric can be cut in critical areas and thus, forming defects can be reduced. Cuts of the fabric, however, interrupt the continuous fibers and thus reduce me chanical performance. By an appropriate assembly of sub preforms, this loss in mechanical performance can be reduced, while drapeability is improved. Suitable strategies for such sub preform assembly strategies are presented and analyzed by Fürst [32].

\subsubsection{Resin injection}

After the preforming process, the subsequent process of resin in jection follows. A comprehensive overview of established Liquid
Composite Molding (LCM) processes is given by Ermanni et al. [33]. In automotive RTM processes, the curing of the highly reactive resins starts while the resin is injected into the heated mold and is finalized after the mold is being filled. In order to shorten cycle time, it is im portant to determine the best suitable reactivity of the resin together with matching process conditions to achieve the gel point right after mold filling. Simulation tools discussed in Sections 4.2 and 4.3 are a key support to determine these conditions. Continuous improvement of the resin systems enable cycle times in the range of $25 \mathrm{~min}$. The processing of highly reactive resins requires special process equipment capable of achieving a homogeneous mixture of the formulation, a fast mold filling and stable reproducible process conditions [34,35]. Two technology types, which enable a fast resin injection and a complete impregnation of the preform for large series production, are called High Pressure Injection RTM (HP IRTM) and High Pressure Compression RTM (HP CRTM) $[36,37]$.

In the HP IRTM process, the preform is positioned in a metal cavity, which subsequently will be closed to the final thickness of the com ponent. Prior to injection the mold is evacuated to prevent the forma tion of air entrapments. The preheated resin with low viscosity is in jected under high pressure, ensuring full impregnation of the preform. Due to high injection rates in closed HP IRTM molds, high cavity pressures up to 100 bars can be reached [14]. This may lead to local fiber movements and undulations, resulting in lower mechanical properties of the part [38]. The injection and venting strategy is of highest importance when optimizing cycle times. In a proper mold, the vents have to be located at the last fill points to ensure a full impreg nation of the part [39 41]. Furthermore, minimizing micro and macro voids formation is of high interest to optimize the part quality [42 44].

HP CRTM comprises two steps: Firstly, the injection step, where the mold is not fully closed, and secondly, the compression step, where the press is closed to reach the aimed fiber volume content and to com pletely impregnate the preform $[14,45,46]$. Therewith, the preform is less compacted, which leads to a high permeability and less pressure increase during injection. In the case of high mold openings, an open gap above the preform arises, which significantly changes the flow and infiltration behavior during injection as now two different flow regions exist: The flow in the porous zone of the preform and the flow in the channel of the open gap [45]. The infiltration of the preform is there fore mainly through the thickness direction which decreases the flow length and therefore allows faster processes. The same characteristic is utilized in the wet molding processes (cf. Section 2.3).

\subsection{Thermoplastic tape forming}

Continuous fiber reinforced thermoplastics (CoFRTP) for auto motive applications are utilizing impregnated and mostly consolidated semi finished products, to achieve short cycle times for component 


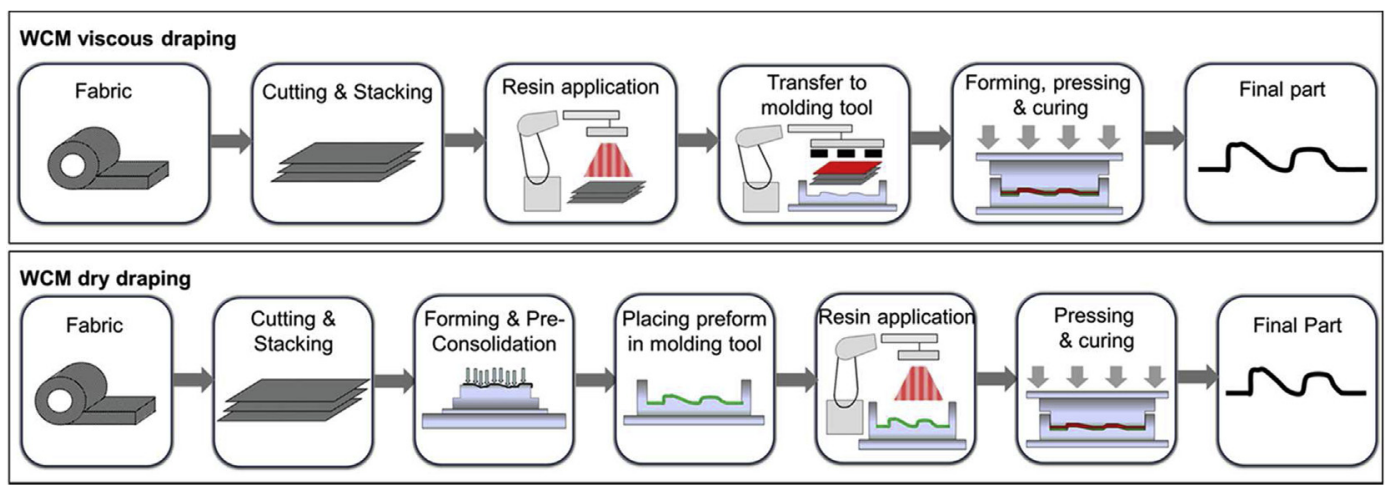

Fig. 3. Two variants of WCM process routes with viscous and dry draping [65].

manufacturing. One exception is the T RTM process, for which a liquid and low viscous monomeric material is injected into a heated mold with a preform, similar to HP IRTM, except that the monomeric material polymerizes in the mold [47 49].

CoFRTP usually consist of a textile semi finished product, which is impregnated by film stacking, powder impregnation or melt impreg nation or comingled fibers with a subsequent consolidation $[1,20]$. These forms of semi finished products reveal distinct anisotropic ma terial properties and a high fiber volume content, accompanied with fiber lengths in part dimension. Suchlike, the finished parts are highly suitable for lightweight structural applications [17 19].

Organosheets and UD tapes are the two semi finished products re levant for automotive applications. Organosheets are supplied as square and fully impregnated and consolidated plates with a woven fiber ar chitecture, whereas UD tapes are supplied as impregnated stripes from a role. UD tapes are the basis for manufacturing of tailored laminates reducing material effort and enabling for highly optimized laminate layups as fibers can be placed at arbitrary positions and in arbitrary directions.

UD tapes are manufactured by tape placement for which mainly two different concepts exist. One processing concept is the often called "in situ thermoplastic tape placement", where single tape layers are locally heated above melting temperature and consolidated layer by layer by applying local pressure. Due to the shape and size of the laying head, which is commonly mounted on industrial robots, the complexity of components is often limited to shell like structures [50]. This process is most suitable for large structures, where long process cycle times are tolerable, such as for aerospace applications.

The second concept is often referred as thermoforming and plays an increasingly important role in the automotive sector due to low cycle times, automatization and recyclability [2,51]. Thermoforming can be divided in three process steps, which namely are the automated tape laying, pre consolidation and thermostamping. For automated tape laying, several stripes of UD tapes are laid adjacent to each other and thus form a single layer of the laminate. Modern tape laying technol ogies are capable to produce highly automatized near net shape layups, with cuts in angles to minimize waste, which is a key requirement in large scale production. The laid laminates are usually ultrasonic spot welded for handling and subsequently consolidated. For pre con solidation, the whole lay up is heated above the melting temperature of the polymer and cooled while applying pressure. In this manner, a monolithic laminate mostly without voids is prepared, which improves final part quality $[52,53]$. In a last step, the consolidated laminates are heated again above melting temperature of the thermoplastic and formed and cooled by a matched die mold, which is heated to a certain temperature $[20,54,55]$. In this context, metal molds are preferred ra ther than one metal and one rubber molds, which were used to improve a homogeneous pressure distribution [56]. Rubber molds are dedicated to distinct degradation as well as to unbalanced residual stresses due to different cooling behavior at the rubber and metal interfaces [57].
During forming, forming defects like wrinkling, gapping or fiber fracture are possible, in analogy to forming of textile fabrics. To influ ence forming behavior in thermoforming processes, grippers can be employed to induce membrane forces [55,58 62]. Grippers are to be preferred rather than blank holders, since blank holders will induce pronounced cooling of the laminate, which tremendously limits form ability.

\subsection{Wet molding with highly reactive thermoset resins}

While HP RTM and tape forming are widely established processes for large volume production, a quasi combination called Wet Compression Molding (WCM) provides even more mass production potential and is being implemented by the automotive industry to further increase the throughput $[63,64]$. However, only little funda mental research has been conducted on the WCM process behavior so far. State of the art is the use of near net shape tailored made fabrics, which are stacked to a certain lay up. Afterwards, the stack can be processed in two process variants, cf. Fig. 3 [65]. In process route 1 (viscous draping), the resin is applied onto the 2D stack and the im pregnated stack is formed into the $3 \mathrm{D}$ part geometry by closing the mold to its final thickness [66]. In contrast, in process route 2 (dry draping), the 2D stack is formed before resin application, in an addi tional preforming step [67]. Therewith, several sub preforms can be assembled to one preform to manufacture complex 3D part geometries. However, process route 2 requires an additional expensive and time consuming preforming step.

The preceding external resin application simplifies the liquid com pression molding process significantly and offers a very economic al ternative to HP RTM [68]. It enables simultaneous curing of one part in the press and applying resin on the fabric of the next part. This tech nology requires either a mold shuttle for the female mold half or, more common, a handling unit which holds the fabric while resin is poured on top. Since the resin injection occurs outside the hot mold, the danger of material curing prior to filling the part is mitigated. Similar to HP CRTM, WCM is also a low pressure process, since the resin is applied at ambient pressure outside of the mold. The superficial application of the resin, with shorter flow paths mainly in thickness direction, allows the use of ultra fast curing resin systems combined with higher mold tem peratures, leading to shorter cure cycles $[65,66]$. With mold tempera tures up to $140{ }^{\circ} \mathrm{C}$, ultra fast curing resin systems enable curing times of $30 \mathrm{~s}$. Fels et al. [69] studied typical process conditions for HP RTM and WCM. While cycle times of approximately $5 \mathrm{~min}$ were reached with HP RTM, the WCM cycle times could be reduced to $2 \mathrm{~min}$, with remarkable $30 \%$ lower press force. Additionally, similar mechanical properties of the WCM and HP RTM composite parts could be achieved [69]. Hence, the WCM process presents an opportunity of reducing the operation cost while maintaining the quality of the product. By separating the resin application from forming and curing, cycle times can be reduced even further to less than 1 min per part [64]. 


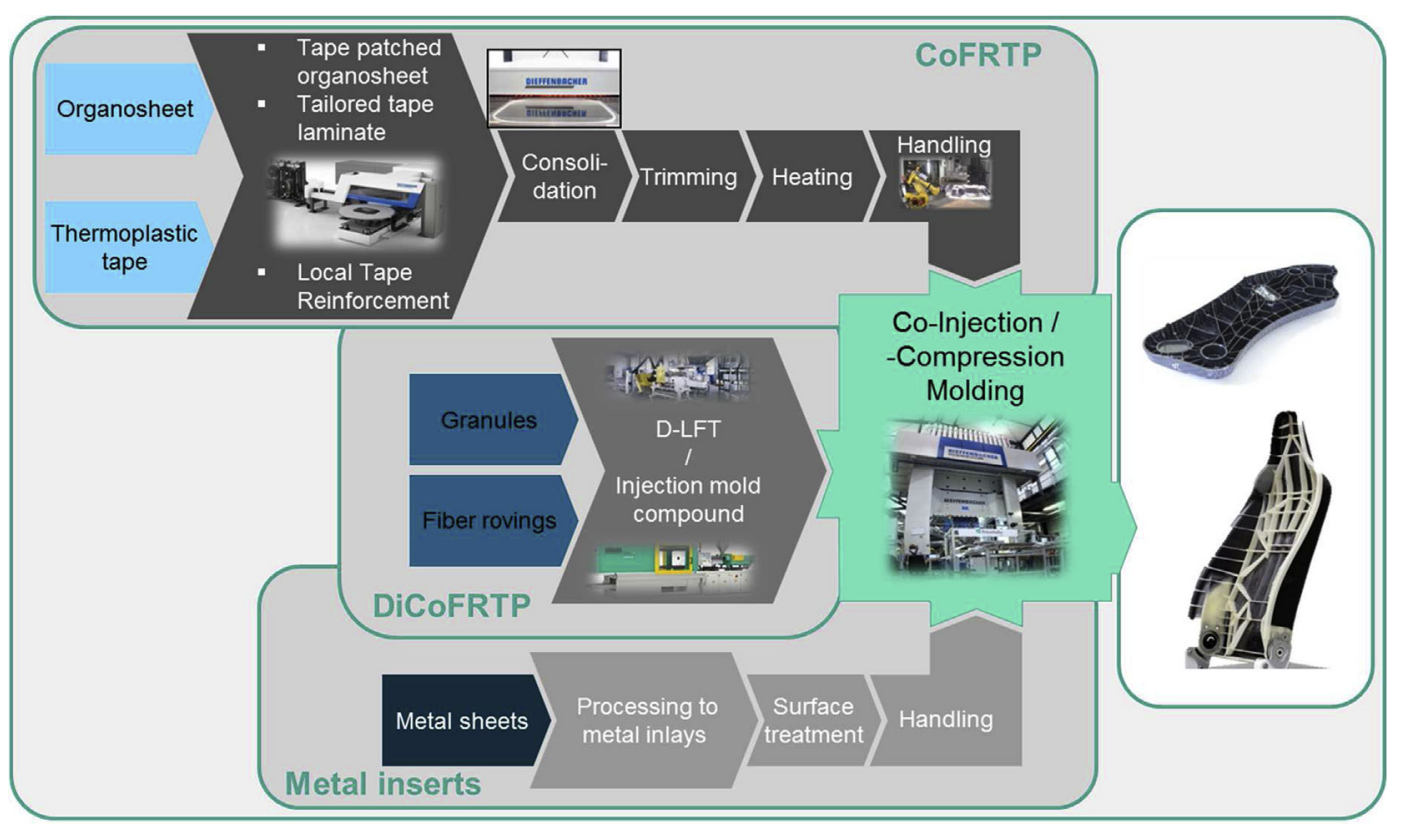

Fig. 4. Process scheme for hybrid thermoplastic CoDicoFRP parts [Fraunhofer ICT].

\subsection{Future trends in automotive composite processing}

In addition to the wet molding process with promising mass pro duction potential, hybridization of each, thermoset and thermoplastic CoFRP is observed as one major future trend for automotive applica tions. On the one hand, functional integration and geometrical stif fening through ribs, clips or pins by co molding of organosheets or tailored blanks with unreinforced thermoplastics or with discontinuous fibre reinforced thermoplastics (DicoFRTP) are in the focus to achieve even more competitive composite components, referred to as CoDicoFRP technology. The second trend in hybridization aims at multi material solutions focusing a system approach by combining CoFRP with metallic inserts for new joining [70,71] or with metallic parts for higher energy absorption capabilities [72]. Fig. 4 shows a process scheme for the production of highly functionally integrated hybrid parts [73,74].

Another important trend is the integration of foam cores to take advantage of the high lightweight potential of sandwich CoFRP [75]. To control the interaction of foam core deformation and cavity pressure, an exact design of the process parameters is necessary [76]. The trend in process technologies is towards low pressure processes, which are less capital intensive, as well as technologies which offer the efficient uti lization of materials, thus reduce production waste and offer highest flexibility in fiber orientation. Reduction of both cavity pressure and process time can be achieved by a so called pressure controlled RTM (PC RTM) process, which uses an integrated cavity pressure control during injection and compression [77]. Extensive research is, however, still needed to ensure a reliable and reproducible intrinsic integration of lightweight foam cores into the RTM process. Another approach to manufacture sandwich CoFRP is the injection molding of a foamed unreinforced thermoplastic core layer between two thermoplastic CoFRP facings [78]. Due to the injection foaming process, a lightweight hybrid sandwich structure can be achieved at very low cycle times but with significantly higher densities than separately foamed and over molded core structures. However, large development potential still exists for three dimensional sandwich structures with complex shape. To meet both requirements maximum use of material at lowest pro duction waste by oriented fiber placement and low pressure processes, tape placement processes will be in the focus of the industry more in tensively in future, either with thermoplastic or thermoset resin systems.

\section{Integrated composite design via continuous simulation chain}

\subsection{Continuous CAE chain}

Three circumstances increase the difficulty of using composites to manufacture automotive components and give reasons for a virtual optimization of process and structural design: First, short cycle times are required, which often demand costly tool development for CoFRP forming and molding. Second, the involved raw materials are mostly expensive and must be used in a part specific optimized way to mini mize material consumption and waste. Third, automotive CoFRP com ponents are often complexly shaped, and their forming process sub stantially changes the fiber structure and influences the injection, solidification and structural behavior. For these reasons, a reliable prediction and optimization of the production process is of utmost importance to ensure high quality and economical production. In pre vious work [79], the authors have shown that a continuous re presentation of the entire composite manufacturing process via a con tinuous virtual process chain (CAE chain) not only yields the prediction of manufacturing effects, it also transfers and accounts for these man ufacturing effects in subsequent simulation steps. Furthermore, a con tinuous CAE chain permits integrated optimization of the process and the structural performance and, thus, has the potential to enhance and accelerate product development [80]. Fig. 5 illustrates the CAE chain as proposed by the authors [79]. In general, the simulation steps may comprise different types of forming (e.g., textile draping, thermo forming, braiding, weaving), molding (e.g., RTM, VARI, wet molding), and solidification (curing, crystallization, cooling), each exhibiting different physical phenomena. To describe these phenomena, different numerical methods with different material models and different ele ment types need to be combined in CAE chains. While the numerical solutions for single process steps are discussed in Section 4 , the de mands and the state of the art of appropriate information transfer be tween these simulation steps are addressed in the current section.

Integrated simulation platforms with mesh based data transfer be tween process simulation and structural simulation domains are well established for metal processing (FEDES [81,82], MpCCI [83], ICME [84]), and for injection molding (Digimat, SIGMASOFT). In contrast, 


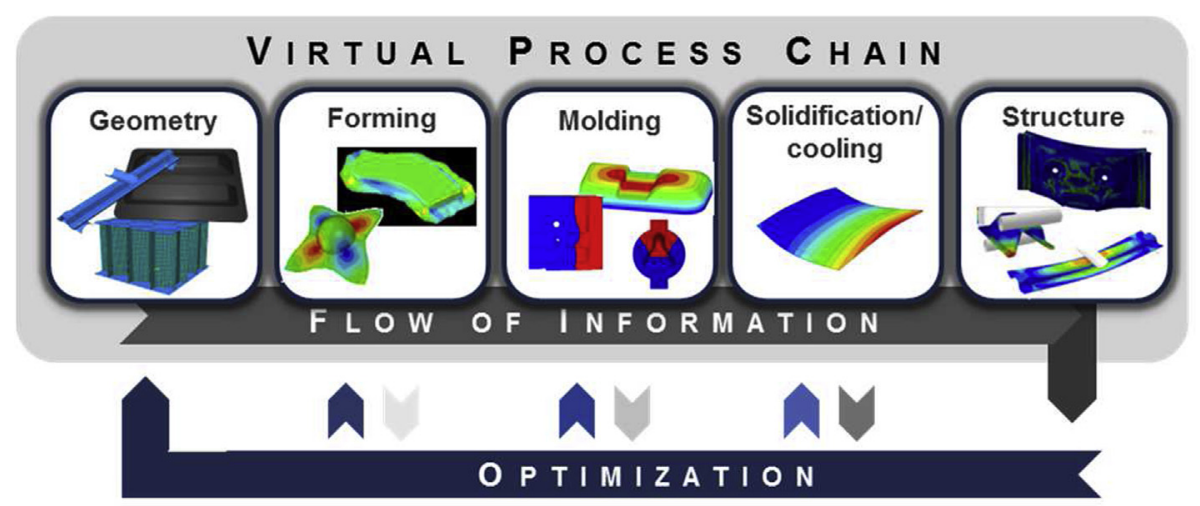

Fig. 5. Virtual Process Chain combining design, process, and structural simulation [79].

the development of CAE chains for CoFRP is still in its early stages and lacks fundamental research in terms of physically consistent informa tion transfer between the simulation steps. While application oriented, commercial in house solutions and corresponding more or less super ficial conference contributions have steadily increased since 2 [85 90], fundamentally orientated journal papers addressing CAE chains for CoFRP are still rare [79,91,92]. In the opinion of the authors, this is mainly caused by the fact that research institutes are typically specia lized in a certain area of expertise, without having the experience and the capacity to look at the whole composite process chain including all intermediate process steps. In this regard, more inter institutional co operation is required and more emphasis has to be put on physically consistent interface solutions, see Section 3.3.

If physical based simulation models for single process steps are combined within a continuous CAE chain, the computational effort rapidly becomes impracticable. To make the solution practicable, sim plifications are often made. Although simplified methods promote the efficiency of continuous CAE chains, they do not always perform re liably, especially for the complex structures needed in automotive ve hicles. For example, a time efficient kinematic forming analysis, as proposed in Refs. [93,94], disregards material properties and boundary conditions and is, thus, unable to reliably predict the fiber structure for complex geometries [62]. Thus, kinematic forming simulation in con tinuous CAE chains, as proposed in Refs. [85,95], should be reserved for cases of simple, one dimensionally curved geometries. For complex automotive structures, the authors suggest to include FE based forming simulation into CAE chains $[79,80]$. In addition to pure simulation chains, manufacturing effects can also be accounted for using known, "as built" data, which may be available from process design data or non destructive testing. A so called feedback method has been devel oped by Kärger and Kling [96], transferring the processed CAD fiber path into structural simulation models and considering curvature in duced stiffness reduction via multi scale analysis. Even closer to ex perimental reality, online process monitoring [90] and CT measure ments $[12,70]$ have been applied to measure fiber orientations, which serve as input for molding, curing or structural simulation. From a scientific point of view, such intermediate consideration of experi mental results is a worthwhile addition to pure virtual CAE chains, enabling a more realistic investigation of specific manufacturing effects. For purposes of product design and product validation prior to manu facturing, however, CAE chains with a continuous virtual descriptions of all intermediate process steps are needed. In both regards, in ex perimental validation and continuous modeling, more fundamental research work is needed to provide a reliable basis for the currently mostly industry driven developments of composite CAE chains.

\subsection{Effects of manufacturing on subsequent process steps and structural} behavior

The topic "effects of defects" and the whole scientific field of pro cess affected material behavior, including failure analysis and damage progression, is far too broad to be discussed in detail in the frame of this feature article with focus on automotive composites. Nevertheless, some important aspects of manufacturing effects are discussed briefly in this section, since the topic provides important motivation for reliable process simulation, for continuous CAE chains and for holistic design of automotive composite components. For complexly curved car struc tures, the forming process is the initial decisive step. Here, the two dimensional textile or pre impregnated material is transformed into a three dimensional near target geometry. Forming is crucial, since the fiber orientation (FO) and fiber volume content (FVC) undergo con siderable change and vary globally. Moreover, local manufacturing defects may occur, such as wrinkling, gapping, and overlaps $[55,97,98]$. Along with the textile type, the layup sequence and process conditions strongly affect the deformation and defect behavior [99], which further illustrates the importance of properly modeling the forming behavior und properly transferring the forming effects to following simulation steps. The forming result has substantial effects on all subsequent process steps. Locally increased shear angles in formed woven fabrics reduce the local permeability and, thus, influence the injection beha vior [95,100 103]. In unidirectional fabrics, the permeability is locally reduced at increased FVC due to superimposed shear strain and trans verse compaction of the fibers $[79,104]$. Race tracking at molding edges additionally affects the injection progress [105]. Variations in FO and FVC also influence the solidification process and, thus, have significant impact on process induced residual stresses and distortion [106]. For example, Steinle [107] found a strong dependency of the torsional deformation of $\mathrm{L}$ section parts on fiber angle deviations in woven tex tiles. Mesogitis et al. [108] give a comprehensive overview of manu facturing uncertainties on composite process results. In the present ar ticle, further aspects of process induced effects are discussed in Section 4.2 regarding mold filling and in Section 4.3 regarding distortion.

Several authors have demonstrated the effects of varying FO and FVC on the mechanical behavior of composite structures. In addition to forming effects, also flow induced voids, dry areas and resin rich zones affect the mechanical properties [108]. At component level and along continuous CAE chains, these effects have been scarcely investigated so far. In this context, the influence on the structural failure behavior $[79,109,110]$ is obviously much more significant than on the global structural stiffness [92]. Compared to component studies, much more investigations have been performed at material level. Particularly, the failure behavior induced by fiber waviness has been investigated [111 114]. In conjunction with the fiber waviness, also the fiber vo lume content shows a significant influence on the composite stiffness $[19,115]$. New failure criteria have been developed to consider the 
influence of fiber misalignments on the failure initiation at compression [116 119]. Despite the previous work and the availability of numerous phenomenological approaches, further experimental investigations and physically consistent model enhancements are needed to ensure general validity. In particular, the combined occurrence of fiber waviness and fiber volume content needs further investigation to fully understand the damage propagation and to enable reliable macroscopic modeling. This is increasingly reasonable, since recent developments in forming si mulation allow predicting local fiber volume content and fiber wavi ness. Using this knowledge, a more realistic prediction of the structural loading capacity can be achieved.

\subsection{Interface solutions for composite CAE chains}

Simulation methods describing the behavior of the individual pro cess steps each have their internal representations of element types and material modeling. In most cases, these representations are in compatible. Thus, model specific data interfaces are needed to transfer information from one simulation step to another. Here, one needs both neutral data formats that ensure software independent data exchange and robust mapping algorithms that ensure accurate information transfer between incompatible meshes [91,120]. Suitable interchange formats can interlink structure mechanical with fluid mechanical models as well as micro mechanical with macro mechanical models, for different types of processes and different length and time scales [84].

The data formats must provide robustness, extensibility, and flex ibility for the types of data being considered [121]. Commonly used interchange formats are HDF5 based [86,91,122], XML based [81,123], and the vtk format [79]. Since a common standard for data interchange formats has not yet been defined, interface implementation requires substantial manual, case by case effort. To reduce case by case adap tion and increase transferability, the European research project ITEA VMAP, started in 2017, aims at the establishment of a new interface standard for integrated virtual material modeling in the manufacturing industry (Wolf 2018). In the VMAP project, the integrated material handling is investigated by six industrial use cases from different manufacturing domains, where the authors coordinate the domain of automotive composite manufacturing.

The development of mapping algorithms for incompatible numer ical meshes was initially undertaken for metal processing applications, and there are many such algorithms available, each with advantages and disadvantages $[120,124]$. For curved and layered CoFRP structures, the meshes for different simulation steps typically exhibit large geo metrical deviations. For instance, forming simulation typically applies layer wise shell element meshes with different mesh shapes and or ientations, whereas molding and structural simulation often represent the whole laminate by a single composite shell element mesh [79]. Moreover, the element sizes usually differ considerably. State of the art mapping solutions apply pragmatic engineering approaches, which are computationally efficient, but partly lack physical justification. Map ping schemes based on the nearest neighborhood search [125] are particularly simple and efficient. Interpolating mapping schemes based on element shape functions seem to be more appropriate [82,91], but still treat tensor components in a decoupled way, which may cause non physical results. If transferred information like fiber orientation, inner stresses, etc. are quantities specific to the integration point, mapping schemes based on integration points are preferable to node based mapping algorithms, which may cause erroneous results particularly in boundary elements [79]. In light of the existing mapping solutions for composite CAE chains, more fundamental mechanical approaches are still needed to interpolate all relevant kinetic and material tensors in a physically consistent way.

\subsection{Integrated optimization of automotive composite processes and structures}

A number of specific optimization methods have been developed for the individual CoFRP process steps. Process optimization typically builds on process simulation methods that do not provide closed form solutions (cf. Section 4). Therefore, genetic algorithms or globalized Nelder Mead algorithms are often used to minimize the objective functions. During textile forming, for instance, textile folding can be avoided by optimizing the lateral clamping arrangement [126]. This optimization approach has been adapted by the authors of the present article to study the influence of draping optimization on structural performance [80], applying the previously published composite CAE chain [79]. Additionally, the authors propose an iterative optimization procedure for the tailoring of the initial blank to achieve waste free composite forming [127]. Apart from numerical approaches, process optimization guidelines based on forming studies have also been de rived to maximize structural performance [128]. While numerical forming optimization is hardly addressed in the literature, molding optimization is much more in focus, for example, to avoid dry spots, control curing, and minimize filling time. Rapid filling, low energy usage, and low investment costs are particularly important for auto motive mass production. To ensure complete filling and sufficient curing during the injection step, gate and vent locations have been optimized [129,130]. For applications in aerospace, temperature and pressure profiles and matrix solidification behavior can be optimized to simultaneously minimize residual stresses and cycle time for autoclave curing [43,131] and for tape placement [132]. Such variable tem perature profiles, however, are not appropriate for fast and automotive suited processes like HP RTM and Wet Compression Molding, where the cure temperature stays at a constant (optimized) level. After demolding, the residual stresses partly dissipate by forming distortions. These dis tortions can be accounted for via iterative optimization of the tooling geometry to finally obtain the target geometry [133]. Another inter esting approach to process optimization is to incorporate uncertainties in material and process parameters, which, for example, can be used to minimize cure cycle times under certain temperature and resin reaction constraints [134].

In addition to the optimization of single process steps, processes and structural performance must be optimized simultaneously to achieve an integrated optimization of CoFRP products. A purely structural ap proach, which only optimizes ply topology and stacking, ignores the crucial question of manufacturability. Hence, process simulation must be performed at least afterwards to check the manufacturability of the optimized design [135]. Deterministic manufacturing constraints are also often included in optimization problems [136 138]. Alternatively, uncertainty parameters can be incorporated into structural design to take manufacturing effects into account [139]. Poorzeinolabedin et al. [140] perform process optimization subsequent to and uncoupled from structural optimization. None of these approaches consider the inter action between process design and structural design, which is particu larly significant for curved CoFRP components. To date, optimization using multiple objectives for both the CoFRP production process and the product's structural performance has scarcely been addressed. Kaufmann et al. [141] introduced a draping knowledge database to include manufacturing costs in the design process of slightly curved prepreg structures. The authors of the present article integrated a ki nematic draping simulation into a patch optimization method for Co DiCoFRP structures [8]. A kinematic model was applied, since FE based forming simulation is considered too costly for the numerous optimi zation loops. Bulla et al. [142] propose a design approach in which a ply wise FE based forming simulation is performed prior to a ply wise topology optimization in order to consider "as manufactured" fiber orientations. Although this approach accounts for initial forming ef fects, it does not consider the feedback loop between the product and the process. For example, when you change the topology of the tailored 


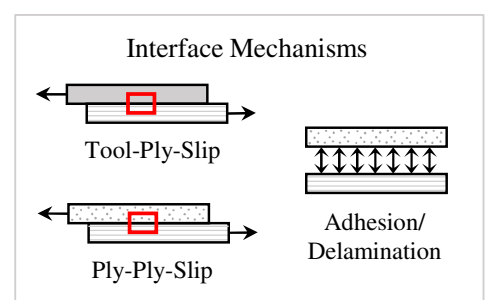

(a)

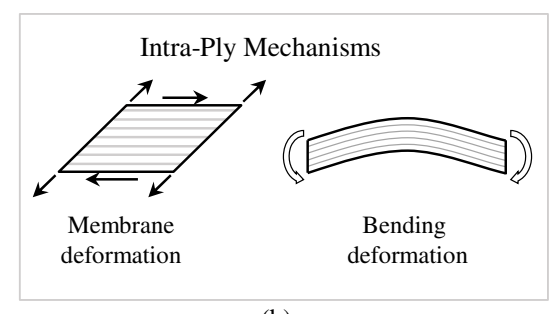

(b)

Fig. 6. Deformation mechanisms during forming of continuously fiber reinforced composites [151].

blank, it affects the process itself. Moreover, contact between adjacent plies is not considered, although it mainly affects the forming behavior. Optimization procedures that include complete FE based process and structural simulations are expensive. To reduce computational effort, complex models are sometimes replaced by simplified analogs, for ex ample, to combine molding and structural optimization $[9,143,144]$ or to combine residual stress and structural optimization [145]. However, these approaches are limited to simple geometries and single process steps.

The authors have introduce a general framework for an integrated optimization workflow including the CAE chain [80]. To cope with the enormous computational effort, the optimization workflow is per formed on a dedicated HPC system, accessible via web based user in terfaces [146]. The CAE workflow is exemplified by automated forming optimization and subsequent structural simulation. An overall auto matic optimization that includes all simulation steps is, however, still too expensive to be executed at once. One conceivable approach to accelerate such multi objective optimizations would be to replace time consuming physics based simulation methods with fast surrogate or meta models. This has been proposed by Nielsen and Pitchumani [147] for quick online optimization of the molding processes and by Carlone et al. [148] to predict the curing process. The authors of the present feature article have proposed different meta modeling strategies to re place physical based forming simulation to optimize the forming per formance $[149,150]$. However, the general question still needs to be answered whether reliable surrogate models can be generated with less computational effort than would be needed to perform the integrated optimization workflow with the physics based complex models. For the time being, an integrated optimization of complex CoFRP structures, including all relevant process and structural aspects along the CAE chain, is still a distant objective.

\subsection{Conclusions and challenges for future automotive composite product development}

To make CoFRP suitable for large scale production, it is essential to further reduce the overall development and production costs of CoFRP parts. Toward that end, as described previously, continuous CAE chains are being increasingly used to capture all relevant process steps and structural characteristics. Despite increasing efforts to develop CAE chains, much research work is still needed to properly establish in tegrated CoFRP product development workflows. The remaining chal lenges can be divided in three clusters: a) simulation models, b) inter face solutions and c) optimization methods. All of these should be as efficient as possible and as reliable as necessary. While a) is discussed in detail in the following sections, the current state of the art for b) and c) has been addressed in this Chapter 3 .

A major drawback of current interface solutions is their lack of a common standard for data interchange formats. Since each research and industrial development group uses its own data format definition, much manual effort is required to develop or adapt case specific in terface solutions. To improve the interface development process, a common, standardized interface solution should be developed that is flexible, robust, and applicable or extendable to a variety of manufacturing processes. Furthermore, improved mechanical ap proaches are needed to interpolate all relevant kinetic and material tensors in a physically consistent way.

Despite the continuously increasing computational performance, an overall automatic optimization along a continuous composite CAE chains, including all intermediate simulation steps, is still far too ex pensive to be executed at once. A conceivable approach to accelerate such multi objective optimizations is the use of numerically efficient surrogate models. However, the computational effort to generate such surrogate models may be very high, even higher than for the integrated optimization using physics based models. Thus, future research is needed to investigate the opportunities and the limits of surrogate modeling to replace physical based models in integrated optimization of automotive composite structures.

Finally, researchers should not lose sight of the experimental vali dation needed to enhance CAE chains and optimization workflows. Most of the literature regarding simulation chains or multi objective optimization is purely numerical. However, studies by the authors on CAE chains with experimental validation [79] show the still limited applicability of series connected process and structural simulation methods.

\section{Molding processes and simulation steps}

\subsection{Forming}

\subsubsection{Forming mechanisms and material characterization}

During forming, so called deformation mechanisms are enforced, which are usually categorized according to intra and inter ply me chanisms (cf. Fig. 6). Due to the very high tensile stiffness in fiber direction, deformation mechanisms are mostly restricted to in plane shear, bending and inter ply slippage, as well as transversal tension for unidirectional reinforcements. Comprehensive reviews on deformation mechanisms can be found in literature [20,54]. To characterize those deformation mechanisms, several material characterization setups are presented in literature, depending on the type of pre product.

Shear characterization. Several setups for shear characterization of CoFRP exist, where it depends on the material system, which is best suited. For characterization of shear behavior of dry or pre impregnated woven or biaxial non crimp fabrics (NCF), usually, the well established trellis frame (picture frame) or uniaxial bias extension test are applied. These tests exhibit several advantages and drawbacks and, as shown in comparative studies [152 154], deliver redundant results solely for isotropic and homogeneous (balanced) woven fabrics. In bias extension tests, tow sliding can occur especially for biaxial NCF [155] and also for woven fabrics, as shown in our previous study [156]. This makes this test more complex to evaluate, since analytical methods fail if tow sliding occurs. On the contrary, the picture frame test prevents tow sliding, but has a high sensitivity to tow misalignment and pre ten sioning. While woven fabrics as well biaxial NCF are investigated in tensively, unidirectional (UD) NCF are investigated only sparsely in literature [157 159]. For characterization of UD NCF, our previous study $[157,160]$ has shown, that solely picture frame tests are in sufficient for characterization of UD NCF, since the intrinsic 
deformation mechanism observed in draping tests is shearing super imposed with transverse tension, which is not invoked by picture frame tests. This makes off axis tension tests including the classical bias ex tension test preferable for characterization of UD NCF. For shear characterization of thermoplastic unidirectional prepregs (UD tapes), usually, the well established rheometer test presented by Haanappel et al. [161] is applied. Haanappel et al. [161] evaluated this test in the small strain regime based on linear visco elasticity theory (LVE). However, since large shear strains outside the LVE are observed during forming and as shown in our previous study [162] material behavior becomes non linear in this regime, the application of this test for large deflections in a transient testing procedure, considering temperature and rate dependency of the material, is preferable.

Bending characterization. Due to the weak bending stiffness of engineering textiles and prepregs, standardized characterization setups following three or four points bending tests are usually not applied, with an exception of the application of these principles for very small specimens [163]. However, employed bending characterization setups for CoFRP are usually based, independent of the material system to be characterized, on the Peirce cantilever test [164 166], a Peirce canti lever enhanced by optical measurements of the specimen [167 169] or the Kawabata bending test [170]. Beyond that, a rheometer setup based on the Kawabate bending principle is presented by Sachs and Akkerman [171]. A comprehensive review of existing variants of these methods is presented by Boisse et al. [172]. The main requirement on bending characterization is the determination of non linear bending behavior depending on curvature, deformation rate and dissipation. Due to its simplicity, often the cantilever test is preferred to determine either a constant bending modulus or a bending moment deflection curve. Based on the enhanced Peirce cantilever test, also dissipative effects can be captured. However, the cantilever test is often accompanied with a twist of the specimen [163], which can lead to a large uncertainty based on the optical determination of the curvature of the specimen. This can be overcome by a vertical alignment of the cantilever test and a custom load application and measurements based on deflection pulleys $[173,174]$. This setup enables also to capture rate dependent bending behavior. However, the custom bending characterization setup pre sented by Sachs and Akkermann [171] enables bending characteriza tion at distinct temperatures and velocity profiles by using the cap abilities of a standard rheometer and thus delivers, in the authors' opinion, the most promising approach for bending characterization, especially for the bending characterization of prepregs.

Friction characterization. Different test setups for friction char acterization at the tool ply and ply ply interfaces are presented in lit erature, where a comprehensive review is presented by Sachs et al. [175]. Benchmark results with different test setups reveal, that basi cally different test setups yield consistent results. Nonetheless, it is observed that friction characterization is prone to systematic errors, where larger friction surfaces, chamfered edge of the friction surfaces and pulling of a metal foil instead of the composite material improved the results. Beyond that, special attention has to be paid to a uniform pressure and temperature distribution in the tested specimen, which makes pull through rather than pull out tests preferable. For en gineering textiles, friction characterization is usually conducted at room temperature. The influence of binders, which are applied for dimen sional stability of preforms prior to the draping process, are neglected so far. Since a distinct influence of binders on frictional behavior is to be expected, future characterization should include the consideration of binders, to enable an optimal design of the draping strategy in terms of temperature control. Regarding prepregs, characterization at elevated temperatures is already well established [175]. Beyond that, ply ply friction characterization is usually conducted with equally oriented plies while neglecting the relative fiber orientation between the slip ping plies. However, our recent studies $[65,176]$ as well as several other authors [177 180] have shown that relative orientation between the sliding plies has a distinct impact on frictional behavior, which should be considered in friction characterization.

\subsubsection{Forming simulation}

For forming simulation of CoFRP, mainly two different modeling approaches exist: the kinematic and the constitutive modeling ap proaches.

Kinematic approaches. Kinematic approaches are based on geo metric mapping algorithms, which transform the initially flat pre pro duct into a three dimensional part, based on the assumption that the deformation of the material is restricted to intra ply shear and by ne glecting material (constitutive) behavior. Based on this, small CPU times typically amounting less than a minute are achievable. Geometrical predictions of woven fabrics were already carried out in the mid '50s [181]. Since then, a lot of research has been done using different mapping approaches [182 185]. In general, kinematic ap proaches require the definition of either a starting point or a starting path as initial situation and the subsequent prediction of fiber or ientation is comparable to an evolving flow. Based on this strategy, beneficial results can be obtained for manual processes like hand draping $[94,186]$ or for automated processes with a symmetrical mold, for which a reasonable definition of the initial situation is amenable. In general, however, kinematic approaches can severely fail, due to the definition of the initial situation for unsymmetrical molds as well as due to the neglected material behavior [187]. Moreover, kinematic ap proaches are limited to single layers and forming processes without any grippers or blank holders to apply membrane forces, since inter ply slippage and boundary conditions are not considered. Beyond that, manufacturing defects like e.g. wrinkling are not predictable due the neglected material behavior.

Constitutive modeling approaches. In contrast to kinematic ap proaches, constitutive modeling approaches consider material behavior and process conditions by means of constitutive equations and boundary conditions, respectively. In this manner, forming defects like wrinkling, fiber fracture or gapping are predictable. Fibrous materials are made up of thousands of fibers and have an internal structure, which make the relative motion of fibers possible during forming. This leads to a very specific material behavior with a very high tensile stiffness in fiber direction and a very low rigidity for every other de formation mode. To account for this specificity in constitutive mod eling, different approaches exist, which mainly can be subdivided into continuous and discrete or mesoscopic approaches. Continuous ap proaches model forming processes in a homogenized manner, whereas in discrete and mesoscopic approaches the single constituents of the material are modelled. For discrete and mesoscopic approaches, less detailed approaches can be applied to forming simulation $[79,98,159,188,189]$, whereas very detailed approaches are applied solely to virtual material characterization [190 194]. An exception are discrete approaches, where only the reinforcement is modelled by (discrete) truss and beam elements $[59,195,196]$. These approaches are comparable efficient as continuous approaches, which use membrane and shell elements, and are straightforward to be implemented by conventional finite elements and constitutive equations.

In the context of automotive composites, efficient numerical ap proaches are necessary for process design. For this reason, continuous approaches, which are usually based on the layer by layer analysis and suitable constitutive equations for the interfaces and the single plies of the stacked laminate, are preferable. Due to the current interest on composite forming, some commercial codes for macroscopic forming simulation are available, which are in particular the AniForm [197] and the PAM Form [198,199] code. Besides this, many continuous ap proaches are presented in literature. Initially, only membrane behavior was considered [26,27,200 202]. However, our recent studies $[151,203]$ as well as other researchers $[172,204,205]$ have shown, that considering of bending is essential for an accurate prediction of wrinkling behavior, which is one of the main defects to be predicted by forming simulation. Another aspect, which is considered only sparsely 


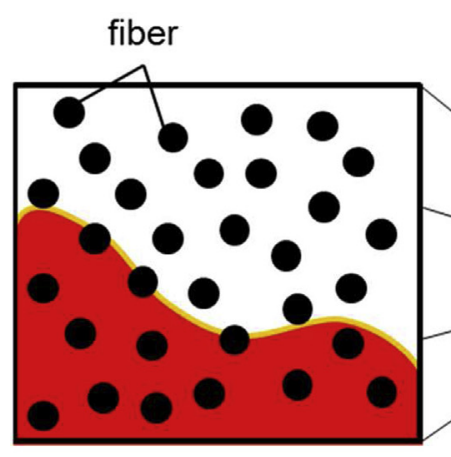

micro-scale

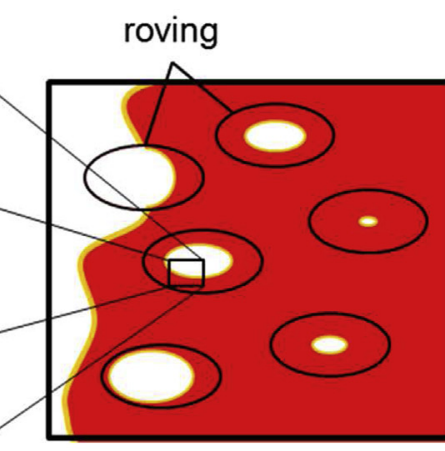

meso-scale

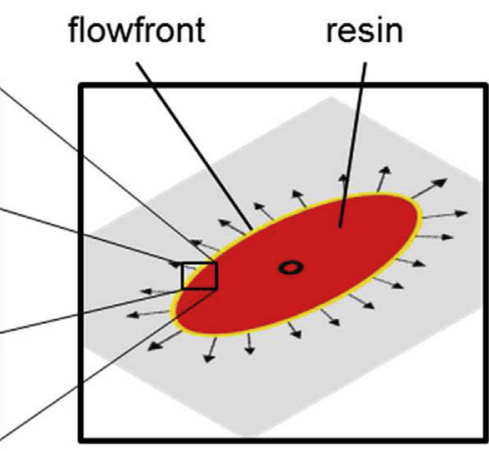

macro-scale

Fig. 7. Micro-, meso- and macro-scale of CoFRP during injection.

so far is thermomechanical modeling of forming processes [206 208]. In our previous study [206], it could be shown that for thermoforming processes the prediction and consideration of temperature and crys tallization of semi crystalline thermoplastics in mechanical modeling of the forming behavior is essential for an accurate prediction of the in fluence of process parameters on forming defects. This is to be expected to be valid also for draping processes of engineering textiles including binders, which is not investigated so far. Besides this, currently much effort is done to further improve material modeling regarding rate de pendency $[162,206]$ and also with respect to dissipative effects for non monotonous loading [209]. Regarding the different types of fiber ar chitectures, a focus on woven textiles can be recognized [210 213] and, in contrast, NCF are only investigated sparsely so far [160,214 216]. Especially for UD NCF, our recently presented approach [160] is, to the authors' knowledge, the only continuous approach presented so far. Since NCF reveal a higher lightweight potential compared to woven fiber architectures, forming simulation of NCF needs to be further in vestigated in the future. The difficulty in this context is to appropriately capture the mesoscopic nature in a macroscopic approach. For this purpose, on the one hand semi discrete $[217,218]$ approaches reveal a promising strategy. On the other hand, higher order gradient ap proaches move more into focus of recent investigations. Such ap proaches enable to account within a continuous for e.g. shear transition zones in which yarns are bent in plane [219] or for intra ply slippage [220].

\subsubsection{Future trends in forming and forming simulation}

One challenge for future research is the combination of CoFRP with other material systems in a multi material design, for example with metals or with discontinuous fiber reinforced polymers (DicoFRP). By combination of both material systems, the full advantage can be exploited, e.g. the high structural performance of CoFRP and the design flexibility of DicoFRP. Automatization and handling manipulation is a further challenge for future research regarding large volume production and short cycle times, in combination with complexly shaped geome tries and a limited formability of CoFRP. In this context, process opti mization regarding near net shape forming and active forming manip ulation is one of the major challenges regarding forming. Therefore, high fidelity forming simulation becomes very important, since virtual analyses can prevent a time and cost expensive "trial and error" process design by virtual process optimization.

While simulation models are mostly well established for woven and biaxial fiber architectures to predict wrinkling behavior, large devel opment potentials exist for unidirectional prepregs and fabrics as well as for triaxial fabrics. This includes the full establishment of thermo mechanical analyses as well as the efficient modeling of the multi scale nature of the formed materials within a continuous approach. For this purpose, higher order gradient approaches reveal a promising strategy. Based on this, more local manufacturing defects than wrinkling as for instance intra ply slip or tow buckling might become predictable.

\subsection{Injection}

\subsubsection{Injection process characteristics}

Subsequent to the forming process, a polymer infiltrates the non impregnated textiles. As described in Section 2.1, the high pressure Resin Transfer Molding (HP RTM) process is currently the most estab lished injection process to achieve low cycle times for automotive composite components. Especially for large scale production in the automotive industry, a low filling time combined with highly reactive matrix systems improves the economic benefit of the RTM process. A reduction of the maximum cavity pressure enables the use of more cost efficient molds and reduced clamping force, which reduces investment costs. Considering traditional RTM, the injection strategy is the most decisive parameter to optimize the injection process. When using RTM variants as Compression RTM, also process parameters like gap height and gap closing velocity have to be chosen adequately [36,221].

In RTM, the infiltration generally shows a multi scale character, which is referred to as micro, meso and macro scale (cf. Fig. 7). The resin flow around fibers inside a roving (micro scale) and between rovings (meso scale) is mainly investigated to predict and minimize voids [42,43] and thus increase mechanical properties of the compo nent.

Simulations on these scales allow to homogenize the permeability for macro scale simulations to predict the form filling on component level [222]. Generally, the anisotropic macro scale permeability beha vior depends on the type of fabric and differs for multidirectional and unidirectional as well as for woven or non crimped fabrics. Ad ditionally, the fiber volume fraction strongly influences the perme ability [104]. As the authors showed, also the used binder type has an influence on the permeability of non crimped fabrics [223], though the cause of this behavior is not yet fully understood and needs further research.

\subsubsection{Simulation of injection processes}

Since a "trial and error" optimization is very expensive and does not guarantee success, mold filling simulations are increasingly used for process optimization. In the automotive industry, macro scale mold filling simulations of large, complex parts are the main application. Simulation of the resin injection is a fluid dynamics problem in porous media, which can be approximated using numerical methods. As a standard in commercial software, the finite element/control volume approach with conforming finite elements [224,225] or non con forming finite elements [130,226] are used. The main issue on devel oping these methods was to ensure mass conservation, which is treated differently in those two mentioned methods.

Another possibility is using the finite volume method, which im plicitly ensures mass conservation. Here, both fluid phases (resin and 
air) are physically modelled and mainly the Volume of Fluid (VoF) approach is used to reconstruct the phase boundary of the fluids. This method also allows modeling the air as compressible fluid and therefore improves the prediction of formation, movement and size of air en trapments. This behavior was investigated by the authors by comparing mold filling simulations of a FE based method to an own developed tool using a FV discretization [227].

One very popular method for an approximation of the permeability based on micro scale assumptions is known as the Gebart model $[77,228]$. New methods use a combination of micro and meso scale CFD simulations to simulate the pressure drop of a fluid flow around fibers inside a roving (micro scale) and between rovings (meso scale). Such multi scale models can be used for homogenization to compute effective permeability values on macro scale [229 232]. However, an injection simulation of a full component using only micro or meso scale models is still not feasible due to limits of computational re sources. Therefore, on macro scale the resin flow in the cavity is typi cally simulated by assuming a fluid flow through a porous medium, captured by Darcy's law. In this case, the permeability is determined experimentally. Though first benchmarks for permeability measure ment exist, there is no established standard test setup yet. The variety of different measurement methods lead to high variations in permeability values, which can have one order of magnitude when using different experimental test set ups [233]. In the second benchmark performed [234], the test set up and the materials were equal in all measurements, which decreased the standard deviation to $20 \%$. Therefore, perme ability measurements are still a research issue, which have to be further investigated and optimized.

As investigated by Bickerton et al. [103,235], the forming process has a big influence on mold filling as it changes fiber orientation and fiber volume fraction locally. Importing the resulting fiber volume fractions and fiber orientations from a forming simulation to a mold filling simulation therefore helps to get a more realistic prediction of the mold filling behavior [104], which is one major point in the CAE chain as proposed by the authors [79]. One newly investigated possi bility is to import fiber structure information from CT data to the si mulation model to be used as input in mold filling simulations, which was shown by the authors using the resin flow around embedded inserts as application example [12].

One recently evolving research area is the simulation of advanced RTM processes as HP CRTM or PC RTM, where the upper mold is moving throughout the process. This leads to a change of the simulation domain during mold filling. One possibility to simulate CRTM is using a FV based flow simulation combined with a dynamic simulation mesh, as proposed by the authors [236]. When furthermore an open gap above the preform occurs, the mold filling simulation has to be mod elled as a combination of a Darcy flow inside the preform and a Stokes flow in the open gap. Additionally, the compaction behavior of the preform has to be included in the simulation, which can be done by using Terzaghi's effective stress formulation and proper constitutive models for the preform deformation [237]. In total, this leads to a complex fluid structure interaction during mold filling and therefore increased simulation effort.

When using very fast curing resin systems, the resin starts to cure already during the injection, which changes its rheological properties. For a detailed analysis of the injection process, the correct modeling of the viscosity, which depends on temperature and curing degree inside the cavity, is getting more important. When simulating a non iso thermal mold filling on macro scale, it was shown that an additional temperature dispersion coefficient has to be included to take account for the temperature and velocity fluctuations on micro scale $[238,239]$.

\subsubsection{Future trends for injection processes}

In automotive application, three major trends influence the research in mold filling simulation. They are namely the demanded higher functionality of the CFRP parts, the development of advanced and flexible new processes or process variants and the use of very fast curing resin systems. All of the mentioned trends are results of the demand of more complex parts and more economic processes to manufacture CoFRP.

To increase the functionality, RTM offers the interesting possibility to embed different types of functional elements into the dry preform. For example an integrated metal insert can facilitate joining process steps and enable detachable connections [71]. However, integrated elements can considerably influence the injection process, as in vestigated by the authors in Seuffert et al. [70] and Magagnato et al. [12]. Another increasing trend is the intrinsic integration of foam cores to fully take advantage of the high lightweight potential of a sandwich CoFRP [75]. To improve the predictability of mold filling, a simulation method with fluid structure interaction (FSI) between the cavity pres sure and the deformation of the foam material has to be used. Especially when using polymer foam cores, an exact design of the process para meters is necessary to deal with the interaction of foam core de formation, cavity pressure and mold temperature [76,240,241]. An open issue when developing a 3D FSI method is, how to treat the massively increasing simulation effort for FSI. Especially when opti mizing process parameters, very fast methods are crucial. Only under these premise, mold filling simulations will be integrated in a compo nent development process.

As some research on the simulation of non isothermal mold filling is already done, a future improvement would be the addition of a non isothermal mold including heat transfer between mold and resin or preform. Very little research is done regarding non isothermal molds and also in recent studies the boundary on the interface between cavity and mold wall is generally assumed to be a constant temperature value $[238,242]$. Especially when injecting a relatively cold resin with high flow rates into a significantly hotter mold to minimize process time, this has to be reconsidered. Though the general numerical formulation of heat transfer in porous media is known [243], a detailed analysis of the temperature inside the cavity and the mold tool, also including the exothermal reaction of the polymer, has still to be done.

Now and even more in future, HP RTM will compete with smart processes, as e.g. controlled Compression RTM variants that offer a high output at significantly lower pressures and therefore lower investments and less operational cost. One example is the high pressure Compression RTM (HP CRTM, cf. Section 2.1.1) where the mold is not completely closed while the resin is injected. Detailed 3D simulation of the HP CRTM injection process is still a complicated task, especially for complex part geometries and parts including inserts, foam cores or different preform layups. New methods to simulate advanced HP CRTM process variants like the pressure controlled RTM (PC RTM [77,244]) were recently developed [245] but further research is to be done. The PC RTM process uses an integrated cavity pressure control during in jection and compression to minimize process time and to enable the use of lightweight foam cores by limiting the maximum cavity pressure. This shows that also in future, the development of the simulation methods and tools always will be influenced by the development of new manufacturing processes.

An emerging manufacturing process, which is related to RTM, is the so called Wet Compression Molding (WCM). WCM consists of a si multaneous combination of forming and infiltration and offers to re duce process time even further, cf. Section 2.3. While for HP RTM a vacuum step is common, it is not state of the art for the WCM process. Thus, a two phase flow of resin and air is expected. In WCM, the resin slowly sinks into the fabric, thus macro voids between the fibers can occur, as confirmed by recent research of the authors [69]. Most of the current WCM applications are simple in their part geometry to avoid a separate preforming step [66]. Nevertheless, current research of the authors investigates the limits of viscous draping and the development and utilization of a CAE chain to describe and optimize the WCM process [65]. The modeling and simulation of the combined infiltration, forming and curing in WCM, but also in the mentioned RTM variants, is 


\section{$\odot=$ point of force application}

a) demolded from lower tool

b) demolded from upper tool

c) demolded from lower tool; poor release effect near the inlet

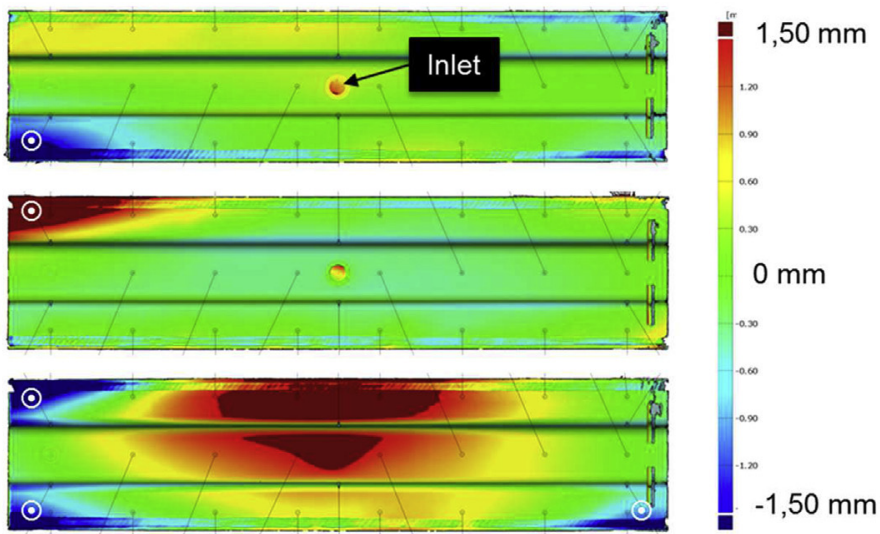

Fig. 8. Influence of demolding conditions on shape deviation of hat profile specimens manufactured using HP-RTM (top view).

a very complex task and is one major future research trend.

Minimizing process time is always limited by the used resin system. For this, the development of fast curing resins that exactly fit the need of a process or even specific component manufacturing parameters is necessary. This leads to a demand in simultaneous resin system, process and component design. Therefore, the resin system has to be added as a design parameter to the CAE chain to allow further optimizing the CoFRP manufacturing and finally boosting their application in future automotive structures.

\subsection{Process induced stresses and distortion}

To assemble automotive structures, the individual parts need to satisfy dimensional tolerances. However, manufacturing of composite structures typically involve formation of process induced residual stresses which lead to warpage and spring in. Strategies for compen sation of the resulting dimensional deviations can be applied either during the design phase with the help of predictive CAE tools or after manufacturing [246]. The latter usually involves deforming the part to fulfill tolerance requirements or shimming existing gaps between as sociated components during assembly. Both techniques are in appropriate in large batch production of automotive composite struc tures, since they involve either high forces or expensive shimming techniques. Therefore, it is worthwhile to consider process induced deformations already during the design process of the part and the corresponding mold.

\subsubsection{Sources of process induced stress}

The sources of process induced residual stresses depend on the matrix material. Curing of thermoset materials is accompanied by chemical shrinkage, whereas thermoplastic polymers show shrinkage strains due to the densification during crystallization. Strains from thermal expansion or contraction are inherent in both material classes. These strains interfere and eventually lead to warpage and spring in of composite parts. Parlevliet et al. [247] provide a comprehensive review on sources of residual stresses in thermoplastic composites, mainly caused by the shrinkage of the matrix. Its magnitude largely depends on material type and processing conditions, e.g. mold temperature, cooling rate and pressure.

In thermoset composites, the contribution of chemical shrinkage to residual stresses can be rather small, if these strains develop at the beginning of the cross linking reaction where the material is highly viscous. This is observed e.g. for BMC and PU composites [248,249]. Additionally, long dwell periods during post cure can lead to stress relaxation and thus to reduced chemical induced residual stresses. This behavior is confirmed also for epoxy resin, where the relaxation times strongly depend on the degree of cure and increase when the cross linking reaction further advances [250,251]. However, in case of cure cycles involving low initial cure temperatures, chemical shrinkage dominates the contribution from thermal strains [252,253]. Therefore, neglecting chemical shrinkage can lead to a significant loss in predic tion quality of warpage simulations [254 256].

Depending on the individual material properties, process induced stresses can lead to lower strength or even pre damage. The actual stress level, however, is strongly influenced by the imposed boundary conditions. Therefore, specimens for corresponding characterization efforts should be manufactured using the exact same process and molding conditions as applied during manufacturing of final composite parts. Regarding processes which involve demolding at high tempera tures, forces applied in order to demold the component give another aspect. Dependent on the part geometry, these forces can induce sub stantial additional stress at a time when the matrix is in rubbery state and therefore is prone to pre damage, stress relaxation and creep. Moreover, demolding often shows low reproducibility depending on the effectiveness of the release agent. As a result, the side of the mold from which the part is demolded varies and so does the effect of applied forces on the shape of the part. This is demonstrated in Fig. 8, which shows the shape deviation of hat profile specimens. As these are iden tical specimens, there is a substantial influence of the individual de molding conditions. However, until now, this aspect has not yet been investigated, although a great amount of investigated specimens should have been affected by this.

\subsubsection{Influencing factors on spring in and warpage}

The dimensional stability of composite structures is strongly af fected by the process induced stresses discussed above through warpage and spring in. The magnitudes of these phenomena can vary sig nificantly. Spring in is mainly caused by anisotropic thermal and che mical shrinkage and typically occurs in curved sections of the part [257 259]. However, it is hard to clearly separate spring in from warpage since they usually superimpose each other [260]. As observed for angled prepreg and RTM specimens, spring in is primarily affected by process parameters and design whereas flange warpage strongly depends on process conditions and tool part interaction [260,261]. The tool material and the layup sequence, on the other hand, have no sig nificant impact on spring in, if the laminate is symmetric. Also, radius and laminate thickness have no influence, if their ratio $(\mathrm{R} / \mathrm{h})$ is greater than unity. In contrast, increased tool angles lead to smaller spring in Ref. [261]. Gradients in fiber volume fraction or due to forced part tool interaction have a large impact on both warpage and spring in by in troducing an asymmetry to the layup [262 265].

Important regarding spring in is the formation of neat resin regions in curved sections with small radii. Such regions result from pre forming, where a gap forms between the concave tool and the textile 
[266,267]. Neat resin regions introduce a strong asymmetry, which counteracts spring in due to high thermal and chemical contraction. The asymmetry effect can be utilized to purposively compensate spring in, e.g. by introducing a deliberate stacking asymmetry in the curved section [268]. However, since preforming conditions are much more complex in reality than for simple L brackets, this effect is hard to control. Moreover, this strategy may lead to an overall higher residual stress level. Therefore, compensating geometrical deviations through process simulation and a tailored mold design should be preferred in stead.

\subsubsection{Analytical and numerical prediction of geometrical deviations}

The use of numerical tools for predicting and minimizing dimen sional instabilities is advantageous for both composite process design including mold optimization and for structural design. However, the approaches presented in literature differ widely. Reasons for this di versity are the variety of process conditions and matrix materials.

Radford and Diefendorf [268] were one of the first to develop an analytical relationship between spring in angle and corresponding sources like thermal and chemical strains. In combination with classical laminated plate theory (CLT), they achieve good prediction accuracy for spring in of prepreg $\mathrm{L}$ section specimens. This approach was reused and adopted by many authors, e.g. for C shaped parts [260] and angled sandwich structures [269]. Ersoy et al. [270] extended the Radford approach by spring in which develops during cool down when the material is not in glassy but in rubbery state, which is often neglected due to low mechanical properties. Causse et al. [271] investigate spring in behavior of curved composite parts manufactured in flexible tools. Flexible tools provoke the accumulation of resin rich zones at inner and outer radius regions as well as the formation of fiber volume fraction gradients. While the Radford based analytical model is unable to render such manufacturing defects, FEM based predictions show good accuracy. Good prediction accuracy by using FEM was also re ported by Darrow and Smith [262] and Fernlund et al. [246]. Kappel et al. [265,272], present a semi numerical distortion simulation strategy by combining experimental, analytical and numerical proce dures. The developed FE method is very efficient due to the use of standard shell elements and the demand of only one input parameter derived from spring in of L profiles. However, the process conditions and laminate design of these $\mathrm{L}$ profiles need to be identical to those of the composite structure. Therefore, their method is most effective in case of large composite structures with few variations in layup config uration and processing as often found in aerospace applications. Au tomotive composite structures, however, are typically of complex geo metry and consist of a variety of different layups. Thus, a method capable of predicting spring in and warpage for arbitrary layups and cure cycles would be more suitable.

Jain et al. [261] investigated the spring in phenomenon using a simple mechanics based model together with a modified shell theory, developed by Jain and Mai [254], and with mechanical properties es timated from micromechanical relationships. Similar approaches are successfully applied by Tzeng [273] and Hyer et al. [274]. Yoon and Kim [252] use the CLT for spring in prediction of L specimens with various $[ \pm \theta] 2$ s layups, showing reasonable accuracy in comparison with experiments. Koller [275] developed approximate equations for the prediction of deformations caused by temperature or moisture gradients. The formulas are applicable to arbitrary unsymmetrical and unbalanced layups, showing very good accuracy in comparison with results of a numerical code.

Visco-elasticity. Several authors have dealt with modeling visco elastic material behavior and resulting residual stresses. However, only few studies are available which apply these models to warpage and spring in simulations. Sunderland et al. [276] developed a numerical tool for predicting evolution and relaxation of internal stresses during thermoplastic composite processing. In experiments, however, warpage was not measured right after demolding, leading to further stress relaxation. Thus, warpage was numerically underestimated by $\sim 50 \%$ [276]. In contrast, later studies with visco elastic approaches over estimate the process induced deformations [277,278]. They suspect that disregarded influences on microstructure level, arising from non crimp fabrics and draping, are the reason for this overestimation. Zarelli et al. [279] modelled the out of plane deflection of a bi material strip specimen, using FEM with visco elastic material models, and achieved good prediction accuracy. In the applied experimental program, the temporal evolution of geometrical deviations is monitored. Such an experimental strategy may be beneficial for future research, since much more data for the validation of complex models with time dependent phenomena is gained. However, it remains unclear to which extent such investigations can be applied to closed mold processes due to a major difference in boundary conditions. Furthermore, fast curing resins as favored by the automotive industry challenge commonly applied ma terial characterization techniques used e.g. for measuring the evolution of relaxation time during curing. Modeling of the latter also requires accurate modeling of the cross linking process and vitrification of the material during isothermal processing, which was investigated by the authors in Bernath et al. [11].

Conclusion on modeling approaches. As shown in the discussion above, many different ways of residual stress predictions have been applied in the past. It is evident that the achieved accuracy is not de pending on the complexity of the used material model. However, complex models are more flexible regarding laminate properties, stacking sequence and cure cycles, since their model do not rely on effective material properties or calibration using simple specimens like $\mathrm{L}$ profiles. This versatility comes at the expense of a higher effort in material characterization and an increase in computational cost. Since the published studies vary largely in material type, laminate parameters and cure cycle conditions, it is difficult to derive universal re commendations regarding which approach is best suited for a specific use case. One major problem is the lack of a reliable method for direct measurement of process induced residual stresses. By establishing such a technique, interpretation and comparison of results from different studies would be much more meaningful.

One fact that is often overlooked is the influence of mold boundary conditions on process induced deformations. As soon as a numerical model accounts for a varying stiffness of the composite during proces sing, this can have a huge impact on predicted deformations since the strain, which develops during demolding, is directly dependent on the current mechanical properties. That said, the attempt to explain me chanisms, acting in a closed mold process, with results derived from specimens that are free to deform during measurement, is likewise prone to errors. Although this gives a more comprehensive insight into the development of residual strains, applicability to structures manu factured under different conditions is limited. This again shows the importance of having reliable characterization methods that enable the observation of these phenomena from inside the mold under conditions comparable to those of the targeted manufacturing process.

\subsubsection{Future trends to predict residual stresses and distortions}

Experimental techniques are needed which allow the direct mea surement of residual stresses in composites without altering the prop erties of the specimens [280]. This is important given the fact that without a reliable measurement, it is hard to compare findings related to the effect of such stresses on the performance of composite structures [259]. Moreover, this would enable model validation on stress level rather than comparing part deformations.

Considering the huge amount of investigated materials, layup con figurations and process conditions, and additionally considering the enormous variety of analytical and numerical models, it would make sense to establish a common foundation for experimental validation of virtual predictions. Thereby, also manufacturing specific sources for additional residual stresses can be investigated with deeper under standing and more reliable conclusion. In this respect, it would be 
worthwhile to investigate the effect of forces, acting during demolding of the part, on the dimensional stability. Recent observations of the authors suggest a significant and material specific influence, capable of outperforming other sources of process induced deformations. Finally, only validated numerical models, which are robust against process and geometrical variations, will be applicable for virtual optimization. For example, robust optimization strategies for mold design will help to minimize residual stresses and dimensional instabilities.

\section{Conclusions and future trends}

Utilizing high performance composites for weight reduction speci fically in automotive applications calls for new application specific process technologies. In contrast to airplanes or luxury cars, automotive mass production requires low cost materials in combination with highly automated and qualified manufacturing technologies. Increased pro ductivity and material efficiency are the main drivers for a successful implementation of composite structures in automotive applications. Such technologies may involve high investment costs, but need to en sure high throughput and affordable operating costs. To simultaneously minimize the process costs, the material costs and the component weight, at ensuring structural integrity, the composite material must be dimensioned and processed with optimized amount and orientation. Therefore, an integrated composite product development must address three areas: simulation and design methods, material sciences and process technologies (MMP approach).

For manufacturing automotive components from continuous fiber reinforced plastics (CoFRP), each process step must be quality assured and fast to achieve cost effective high volume production. Furthermore, processes must be capable to realize complex component shapes. The most common CoFRP processes that provide high productivity and high geometrical complexity are High Pressure Resin Transfer Molding (HP RTM), Wet Compression Molding (WCM) and tape forming. While HP RTM and tape forming have both been widely investigated in literature, only little research has yet been conducted on WCM. In contrast to the scientific world, automotive industry has well recognized the potential of WCM and is already implementing this cost efficient process for car component manufacturing. However, the material behavior during WCM is hardly understood, and extensive experimental and numerical research work is required to understand the process and push its limits.

The most efficient impregnation is UD Tape based, either thermo plastic or thermoset based. UD structures show the most uniform mi croscopic homogeneous distribution of filaments at lowest degree of undulation compared to fabrics, avoiding resin and fiber rich areas in between and at the crossing of warp and weft threads. Latest trends in efficient tape placement lead to short cycle time as well as low pro duction waste at optimized fiber orientation in the part.

Besides WCM and tape placement processes, another big trend for car manufacturing with composites is the combination of different material systems and processes. Such multi material design utilizes the material specific benefits in an optimal way and can exploit the full advantage. Current research topics are, for example, the integration of foam cores in HP RTM, the combination of discontinuous FRP (DicoFRP) compression molding or DicoFRP back injection with metal or CoFRP sheets.

Integrated virtual optimization of the composite processes and the structural integrity requires suitable simulation methods combined with reliable material characterization. To predict the process behavior, the solidification of the polymer material is of crucial importance. For fast curing thermosets as well as for thermoplastic processes with high cooling rates, enhanced material models and enhanced characterization methods at process relevant conditions are required. In automotive CoFRP processes, the solidification must be considered already during injection and, for prepregs, during forming. Forming and injection comprise completely different physical phenomena, one of continuum mechanics nature and the other one of fluid mechanics nature.
Consequently, different simulation approaches are applied and different scientific communities are working on these topics. For forming simu lation, particularly unidirectional and triaxial fabrics, but also UD prepreg materials, hold large development potential, while well estab lished methods exist for biaxial fabrics. Injection simulation of CoFRP is a much older research field than CoFRP forming simulation, providing well established models for one and two phase fluid simulations. A younger research focus, particularly for complexly curved automotive components, is the influence of the local fiber architecture and fiber volume fraction on the injection behavior. Furthermore, advanced pressure controlled RTM and WCM processes provide new potential and new challenges for virtual process optimization. Looking at the big trends in automotive composite processes, WCM and multi material processes, simultaneous forming and injection is one of the most sig nificant subjects for future research in composite process simulation.

Finally, a continuous representation of the whole CoFRP process chain, which includes all intermediate process steps, is a necessary precondition for holistic process and structural design. Although con tinuous CAE chains are being increasingly developed and used to cap ture all relevant process steps, much research work is still needed to properly establish CoFRP product development workflows. Physical based simulation models involve large computation times, while short computation times are desirable for product optimization. Therefore, a major challenge for future research is either to speed up physical based models or to develop sophisticated meta models for process and structural optimization.

\section{Acknowledgements}

The authors are grateful for the public funding of basic research projects, which enable to trace the state of the art and push it forward at one point or another. Worth mentioning in particular are: the Vector Foundation for funding the Young Investigator Group "Green Mobility Tailored Composite Materials for Lightweight Vehicles", the Federal Ministry of Education and Research (BMBF) for funding the project "SMiLE System integrated multi material lightweight design for electromobility" and the project "MoPaHyb Modular production fa cility for hybrid parts", the German Research Foundation (DFG) for funding the priority program 1712 (SPP1712) "Intrinsic hybrid com posites for lightweight load bearing structures", the project "Experimental and virtual analysis of draping effects" and the International Research Training Group "Integrated engineering of continuous discontinuous long fiber reinforced polymer structures" (DFG GRK 2078) and, finally, the Baden Württemberg State Ministry of Science, Research and the Arts (MWK) for just recently funding the project "Time and cost efficient process and product development for high performance fiber composite design using wet molding tech nology".

\section{References}

[1] F. Henning, E. Moeller (Eds.), Handbuch Leichtbau: Methoden, Werkstoffe, Fertigung. München, Hanser Verlag, 2011.

[2] E.R. Fuchs, F.R. Field, R. Roth, R.E. Kirchain, Strategic materials selection in the automobile body: economic opportunities for polymer composite design, Compos. Sci. Technol. 68 (9) (2008) 1989-2002.

[3] P. Beardmore, C.F. Johnson, The potential for composites in structural automotive applications, Compos. Sci. Technol. 26 (4) (1986) 251-281.

[4] K. Friedrich, A.A. Almajid, Manufacturing aspects of advanced polymer composites for automotive applications, Appl. Compos. Mater. 20 (2) (2013) 107-128.

[5] U. Vaidya, Composites for Automotive, Truck and Mass Transit: Materials, Design, Manufacturing, DEStech Publ, Lancaster, Pa., 2011.

[6] S. Hale, Lightweighting Automotive Materials for Increased Fuel Efficiency and Delivering Advanced Modeling and Simulation Capabilities to U.S. Manufacturers, Final Technical Report (2013).

[7] D.M. Corbridge, L.T. Harper, D de Focatiis, N.A. Warrior, Compression moulding of composites with hybrid fibre architectures, Compos. Part A Appl. Sci. Manuf. 95 (2017) 87-99.

[8] B. Fengler, L. Kärger, F. Henning, A. Hrymak, Multi-objective patch optimization with integrated kinematic draping simulation for continuous-discontinuous fiber- 
reinforced composite structures, J. Compos. Sci. 2 (2) (2018) 22.

[9] B. Eck, S. Comas-Cardona, C. Binetruy, C. Aufrere, Multi-objective composite part mechanical optimization enhanced by a process estimator, Compos. Struct. 119 (2015) 620-629.

[10] T. James, Characterization and simulation of structural fabrics - Part 1: a crossindustry review of approaches to composites engineering, Reinforc. Plast. 59 (2) (2015) 94-99.

[11] A. Bernath, L. Kärger, F. Henning, Accurate cure modeling for isothermal processing of fast curing epoxy resins, Polymers 8 (11) (2016) 390

[12] D. Magagnato, J. Seuffert, A. Bernath, L. Kärger, F. Henning, Experimental and numerical study of the influence of integrated load transmission elements on filling behavior in resin transfer molding, Compos. Struct. 198 (2018) 135-143.

[13] P. Bussetta, N. Correia, Numerical forming of continuous fibre reinforced composite material: a review, Compos. Part A Appl. Sci. Manuf. 113 (2018) 12-31.

[14] P. Rosenberg, R. Chaudhari, M. Karcher, F. Henning, P. Elsner, Investigating cavity pressure behavior in high-pressure RTM process variants, Proceedings PPS-29: the 29th International Conference of the Polymer Processing Society, Nuremberg, Germany, 15-19 July 2013.

[15] F. Nosrat Nezami, T. Gereke, C. Cherif, Active forming manipulation of composite reinforcements for the suppression of forming defects, Compos. Part A Appl. Sci. Manuf. 99 (2017) 94-101.

[16] T. Gereke, O. Döbrich, M. Hübner, C. Cherif, Experimental and computational composite textile reinforcement forming: a review, Compos. Part A Appl. Sci. Manuf. 46 (2013) 1-10.

[17] S. Pansart, M. Sinapius, U. Gabbert, A comprehensive explanation of compression strength differences between various CFRP materials: micro-meso model, predictions, parameter studies, Compos. Part A Appl. Sci. Manuf. 40 (4) (2009) 376-387.

[18] B.D. Allison, J.L. Evans, Effect of fiber waviness on the bending behavior of Sglass/epoxy composites, Sustain. Mater. Des. Appl. 36 (2012) 316-322.

[19] M.R. Garnich, G. Karami, Finite element micromechanics for stiffness and strength of wavy fiber composites, J. Compos. Mater. 38 (4) (2004) 273-292.

[20] A.C. Long, Design and Manufacture of Textile Composites, Woodhead; CRC, Cambridge, Boca Raton, 2005.

[21] M.H. Kashani, A. Rashidi, B.J. Crawford, A.S. Milani, Analysis of a two-way tension-shear coupling in woven fabrics under combined loading tests: global to local transformation of non-orthogonal normalized forces and displacements, Compos. Part A Appl. Sci. Manuf. 88 (2016) 272-285.

[22] F. Nosrat-Nezami, T. Gereke, C. Eberdt, C. Cherif, Characterisation of the shear-tension coupling of carbon-fibre fabric under controlled membrane tensions for precise simulative predictions of industrial preforming processes, Compos. Part A Appl. Sci. Manuf. 67 (2014) 131-139.

[23] M. Komeili, A.S. Milani, On effect of shear-tension coupling in forming simulation of woven fabric reinforcements, Compos. Part B Eng. 99 (2016) 17-29.

[24] S. Allaoui, C. Cellard, G. Hivet, Effect of inter-ply sliding on the quality of multilayer interlock dry fabric preforms, Compos. Part A Appl. Sci. Manuf. 68 (2015) 336-345.

[25] S. Allaoui, G. Hivet, D. Soulat, A. Wendling, P. Ouagne, S. Chatel, Experimental preforming of highly double curved shapes with a case corner using an interlock reinforcement, Int. J. Mater. Form. 7 (2) (2014) 155-165.

[26] H. Lin, J. Wang, A.C. Long, M.J. Clifford, P. Harrison, Predictive modelling for optimization of textile composite forming, Compos. Sci. Technol. 67 (15-16) (2007) 3242-3252.

[27] J.S. Lee, S.J. Hong, W.-R. Yu, T.J. Kang, The effect of blank holder force on the stamp forming behavior of non-crimp fabric with a chain stitch, Compos. Sci. Technol. 67 (3-4) (2007) 357-366.

[28] E. Capelle, P. Ouagne, D. Soulat, D. Duriatti, Complex shape forming of flax woven fabrics: design of specific blank-holder shapes to prevent defects, Compos. Part B Eng. 62 (2014) 29-36.

[29] A.R. Labanieh, C. Garnier, P. Ouagne, O. Dalverny, D. Soulat, Intra-ply yarn sliding defect in hemisphere preforming of a woven preform, Compos. Part A Appl. Sci. Manuf. 107 (2018) 432-446.

[30] P. Ouagne, D. Soulat, J. Moothoo, E. Capelle, S. Gueret, Complex shape forming of a flax woven fabric; analysis of the tow buckling and misalignment defect, Compos. Part A Appl. Sci. Manuf. 51 (2013) 1-10.

[31] C. Tephany, J. Gillibert, P. Ouagne, G. Hivet, S. Allaoui, D. Soulat, Development of an experimental bench to reproduce the tow buckling defect appearing during the complex shape forming of structural flax based woven composite reinforcements, Compos. Part A Appl. Sci. Manuf. 81 (2016) 22-33.

[32] T. Fürst, Experimentelle Charakterisierung von Designvarianten überlappend gefügter Kohlenstofffaserverbundstrukturen im Kontext der Entwicklung neuartiger Drapiertechnologien, Karlsruhe, Germany, $2017 \mathrm{PhD}$ Thesis (in German).

[33] P. Ermanni, C. Di Fratta, F. Trochu, Molding: liquid composite molding (LCM), in: L. Nicolais (Ed.), Wiley Encyclopedia of Composites, John Wiley \& Sons, Inc, Hoboken, NJ, USA, 2011.

[34] R. Chaudhari, M. Karcher, P. Elsner, F. Henning, Characterization of high pressure RTM for manufacturing of high performance composites, Proceedings of ECCM15 European Conference on Composite Materials, Venice, 2012.

[35] M. Deléglise, P. Le Grognec, C. Binetruy, P. Krawczak, B. Claude, Modeling of high speed RTM injection with highly reactive resin with on-line mixing, Compos. Part A Appl. Sci. Manuf. 42 (10) (2011) 1390-1397.

[36] S. Bickerton, M.Z. Abdullah, Modeling and evaluation of the filling stage of injection/compression moulding, Compos. Sci. Technol. 63 (10) (2003) 1359-1375.

[37] M.K. Kang, W. Il Lee, Analysis of resin transfer/compression molding process, Polym. Compos. 20 (2) (1999) 293-304.

[38] R. Chaudhari, Characterization of High-pressure Resin Transfer Molding Process Variants for Manufacturing High-performance Composites, PhD Thesis (2013).
[39] A. Saad, A. Echchelh, M. Hattabi, M. El Ganaoui, Optimization of the cycle time in resin transfer molding process by numerical simulation, J. Reinforc. Plast. Compos. 31 (20) (2012) 1388-1399.

[40] M.Y. Lin, M.J. Murphy, H.T. Hahn, Resin transfer molding process optimization, Compos. Part A Appl. Sci. Manuf. 31 (4) (2000) 361-371.

[41] A. Boccard, W.I. Lee, G.S. Springer, Model for determining the vent locations and the fill time of resin transfer molds, J. Compos. Mater. 29 (3) (1995) 306-333.

[42] J. Schell, M. Deleglise, C. Binetruy, P. Krawczak, P. Ermanni, Numerical prediction and experimental characterisation of meso-scale-voids in liquid composite moulding, Compos. Part A Appl. Sci. Manuf. 38 (12) (2007) 2460-2470.

[43] E. Ruiz, F. Trochu, Multi-criteria thermal optimization in liquid composite molding to reduce processing stresses and cycle time, Compos. Part A Appl. Sci. Manuf. 37 (6) (2006) 913-924.

[44] D.H. Lee, W.I. Lee, M.K. Kang, Analysis and minimization of void formation during resin transfer molding process, Compos. Sci. Technol. 66 (16) (2006) 3281-3289.

[45] P. Bhat, J. Merotte, P. Simacek, S.G. Advani, Process analysis of compression resin transfer molding, Compos. Part A Appl. Sci. Manuf. 40 (4) (2009) 431-441.

[46] P. Simacek, S.G. Advani, S.A. Iobst, Modeling flow in compression resin transfer molding for manufacturing of complex lightweight high-performance automotive parts, J. Compos. Mater. 42 (23) (2008) 2523-2545.

[47] Bitterlich Mea, Tailored to reactive polyamide 6, Kunstst. Int. 104 (3) (2014) 47-51.

[48] M. Ehleben, M. Bitterlich, O. Träger, Thermoplastic resin transfer moulding (TRTM) and hybrid press injection moulding, Schriftenreihe Kunststofftechnik (VDI) (4337) (2015) 91-103.

[49] S. Schmidhuber, E. Fries, P. Zimmermann, It couldn't Be more hybrid - thermoplastic-matrix RTM on the roof frame of the roding roadster, Kunstst. Int. (1-2) (2017) 36-38.

[50] Z. Qureshi, T. Swait, R. Scaife, H.M. El-Dessouky, In situ consolidation of thermoplastic prepreg tape using automated tape placement technology: potential and possibilities, Compos. Part B Eng. 66 (2014) 255-267.

[51] J. Verrey, M.D. Wakeman, V. Michaud, J.-A. Månson, Manufacturing cost comparison of thermoplastic and thermoset RTM for an automotive floor pan, Compos. Part A Appl. Sci. Manuf. 37 (1) (2006) 9-22.

[52] A. Schug, D. Rinker, R. Hinterhoelzl, K. Drechsler, Evaluating the potential of forming spot-welded layups out of fibre reinforced thermoplastic tape without previous consolidation, Int. J. Mater. Form. 43 (22) (2018) 41.

[53] T.K. Slange, L.L. Warnet, W. Grouve, R. Akkerman, Deconsolidation of C/PEEK blanks: on the role of prepreg, blank manufacturing method and conditioning, Compos. Part A Appl. Sci. Manuf. 113 (2018) 189-199.

[54] P. Boisse (Ed.), Advances in Composites Manufacturing and Process Design, Woodhead Publishing, Cambridge UK, 2015.

[55] T. Joppich, D. Doerr, L. van der Meulen, T. Link, B. Hangs, F. Henning, Layup and process dependent wrinkling behavior of PPS/CF UD tape-laminates during nonisothermal press forming into a complex component, Proceedings 19th ESAFORM Conference, Nantes, 2016.

[56] G. Sala, A numerical and experimental approach to optimise sheet stamping technologies: Part II: aluminium alloys rubber-forming, Mater. Des. 22 (4) (2001) 299-315.

[57] S. Wijskamp, Shape Distortions in Composites Forming, PhD Thesis. Twente, Enschede, The Netherlands (2005).

[58] B. Zhu, T.X. Yu, H. Zhang, X.M. Tao, Experimental investigation of formability of woven textile composite preform in stamping operation, Int. J. Mater. Form. 1 (1) (2008) 969-972.

[59] P. Harrison, R. Gomes, N. Curado-Correia, Press forming a 0/90 cross-ply advanced thermoplastic composite using the double-dome benchmark geometry, Compos. Part A Appl. Sci. Manuf. 54 (2013) 56-69.

[60] K. Vanclooster, S. van Goidsenhoven, S.V. Lomov, I. Verpoest, Optimizing the deepdrawing of multilayered woven fabric composites, Int. J. Mater. Form. 2 (1) (2009) 153.

[61] U. Breuer, M. Neitzel, V. Ketzer, R. Reinicke, Deep drawing of fabric-reinforced thermoplastics: wrinkle formation and their reduction, Polym. Compos. 17 (4) (1996) 643-647.

[62] K. Vanclooster, Forming of Multilayerd Fabric Reinforced Thermo-plastic Composites, PhD Thesis (2009) Leuven, Belgien.

[63] Rehmet P. CFK-Bauteile in immer kürzeren Taktzeiten: Pressemitteilung JEC World Composites Show \& Conferences; Available from: http://www. kraussmaffeigroup.com/media/files/kmnews/de/PM RPM 201602 JEC de.pdf.

[64] Sloan J. Huntsman announces 60-second cycle times with compression process; Available from: http://www.compositesworld.com/news/huntsman-announces60-second-cycle-times-with-compression-process.

[65] J. Hüttl, F. Albrecht, C. Poppe, F. Lorenz, B. Thoma, L. Kärger, et al., Investigation on friction behaviour and forming simulation of plain woven fabrics for wet compression moulding, Proceedings SAMPE Europe Conference, 2017.

[66] S.J. Stanglmaier, Empirische Charakterisierung und Modellierung des Imprägnierprozesses lokal verstärkter Kohlenstofffaserhalbzeuge im RTM- und Nasspress-Verfahren für die Großserie, (2017) PhD Thesis (in German).

[67] K. Heudorfer, S. Carosella, P. Middendorf, Compression wet moulding as alterative to RTM, Proceedings 25, Stuttgarter Kunststoffkolloquium, Stuttgart, 2017.

[68] J. Bergmann, H. Dörmann, R. Lange, Interpreting process data of wet pressing process. Part 1: theoretical approach, J. Compos. Mater. 50 (17) (2016) 2399-2407.

[69] J. Fels, G. Meirson, V. Ugresic, P. Dugsin, F. Henning, A. Hrymak, Mechanical property difference between composites produced using vacuum assisted liquid compression molding and high pressure resin transfer molding, Proceedings ACCE2017 - 17th Annual Automotive Composites Conference and Exhibition, 
Michigan, 2017.

[70] J. Seuffert, L. Kärger, F. Henning, Simulation of the influence of embedded inserts on the RTM filling behavior considering local fiber structure, KEM 742 (2017) 681-688.

[71] J. Gebhardt, F. Pottmeyer, J. Fleischer, K. Weidenmann, Characterization of metal inserts embedded in carbon fiber reinforced plastics, MSF 825-826 (2015) 506-513.

[72] M. Dlugosch, J. Fritsch, D. Lukaszewicz, S. Hiermaier, Experimental investigation and evaluation of numerical modeling approaches for hybrid-FRP-steel sections under impact loading for the application in automotive crash-structures, Compos. Struct. 174 (2017) 338-347.

[73] F. Henning, T. Joppich, S. Kilian, S. Baumgärtner, T. Link, D. Dörr, Economical Manufacturing of Hybrid Thermoplastic Composites - a Technology Update, (2017) Stuttgart.

[74] M. Schuck, Vereinte Prozesse für hohe Funktionsintegration, Lightweight Des. 8 (5) (2015) 14-19.

[75] A. Al-Hamdan, M. Al-Ajloni, M. Alhusein, C.D. Rudd, A.C. Long, Behaviour of core materials during resin transfer moulding of sandwich structures, Mater. Sci. Technol. 16 (7-8) (2000) 929-934.

[76] J. Gerstenkorn, M. Kothmann, G. Deinzer, L. Kärger, F. Henning, Characterization of the multi-axial material behavior of polymer foams during the RTM process, Proceedings of ECCM17 - European Conference on Composite Materials, Munich, 2016.

[77] G. Deinzer, M. Kothmann, D. Roquette, F. Diebold, AUDI Ultra-RTM: a technology for high performance and cost effective CFRP parts for high volume production, Proceedings of ECCM17 - European Conference on Composite Materials, Munich, 2016.

[78] A. Menrath, F. Henning, T. Huber, A. Roch, C. Riess, Foam-injected sandwich panels with continuous-reinforced facings, Proceedings PPS-29: the 29th International Conference of the Polymer Processing Society, Nuremberg, Germany, 15-19 July 2013.

[79] L. Kärger, A. Bernath, F. Fritz, S. Galkin, D. Magagnato, A. Oeckerath, et al., Development and validation of a CAE chain for unidirectional fibre reinforced composite components, Compos. Struct. 132 (2015) 350-358.

[80] L. Kärger, S. Galkin, C. Zimmerling, D. Dörr, J. Linden, A. Oeckerath, et al., Forming optimisation embedded in a CAE chain to assess and enhance the structural performance of composite components, Compos. Struct. 192 (2018) 143-152.

[81] S.M. Afazov, Modelling and simulation of manufacturing process chains, CIRP J. Manuf. Sci. Technol. 6 (1) (2013) 70-77.

[82] S.M. Afazov, A.A. Becker, T.H. Hyde, Development of a finite element data exchange system for chain simulation of manufacturing processes, Adv. Eng. Software 47 (1) (2012) 104-113.

[83] S.C.A.I. Fraunhofer, MetalMapper 4.4 Documentation, Sankt Augustin (2015).

[84] G.J. Schmitz, U. Prahl (Eds.), Integrative Computational Materials Engineering: Concepts and Applications of a Modular Simulation Platform, Wiley-VCH, Weinheim Germany, 2012.

[85] M. Chatiri, T. Schuetz, A. Matzenmiller, Crashworthy design of composite structures using CAE process chain, 10th European LS-DYNA Conference 2015, Würzburg, 2015.

[86] J. Dittmann, D. Michaelis, P. Böhler, P. Middendorf, DigitPro - validating the link between braiding simulation, infiltration and mechanical testing, Proceedings of ECCM17 - European Conference on Composite Materials, Munich, 2016.

[87] F. Masseria, A. Berger, B. Kaiser, Virtual composite manufacturing simulation chain, MSF 825-826 (2015) 671-676.

[88] L. Kärger, A. Schön, F. Fritz, P. Böhler, D. Maganato, S. Fischer, F. Henning, Virtual Process Chain for an integrated assessment of high-performance composite structures, Proceedings NAFEMS World Congress, Salzburg, 2013.

[89] M. Dix, S. Bickerton, M. Tryfonifis, R. Hinterhölzl, Consistent virtual CFRP process chain using a modular CAE interface, Proceedings NAFEMS World Congress, Salzburg, 2013.

[90] C. Brauner, A. Miene, A. Herrmann, M. Bruyneel, F. Pascon, Virtual process chain combined with online process monitoring for first time right manufacturing of composite structures, Proceedings NAFEMS Seminar Simulation, Leipzig, 2014, pp. 302-311.

[91] N. Mayer, B. van den Broucke, J. Prowe, T. Havar, R. Hinterhölzl, Finite element mapping for incompatible FE meshes of composite structures, Adv. Eng. Software 99 (2016) 81-88.

[92] N. Mayer, J. Prowe, T. Havar, R. Hinterhölzl, K. Drechsler, Structural analysis of composite components considering manufacturing effect, Compos. Struct. 140 (2016) 776-782.

[93] P. Potluri, S. Sharma, R. Ramgulam, Comprehensive drape modelling for moulding 3D textile preforms, Compos. Part A Appl. Sci. Manuf. 32 (10) (2001) 1415-1424.

[94] S.G. Hancock, K.D. Potter, The use of kinematic drape modelling to inform the hand lay-up of complex composite components using woven reinforcements, Compos. Part A Appl. Sci. Manuf. 37 (3) (2006) 413-422.

[95] S. Bickerton, P. Šimáček, S.E. Guglielmi, S.G. Advani, Investigation of draping and its effects on the mold filling process during manufacturing of a compound curved composite part, Compos. Part A Appl. Sci. Manuf. 28 (9-10) (1997) 801-816.

[96] L. Kärger, A. Kling, As-built FE simulation of advanced fibre placement structures based on manufacturing data, Compos. Struct. 100 (2013) 104-112.

[97] L.M. Dangora, C.J. Mitchell, J.A. Sherwood, Predictive model for the detection of out-of-plane defects formed during textile-composite manufacture, Compos. Part A Appl. Sci. Manuf. 78 (2015) 102-112.

[98] P. Böhler, F. Härtel, P. Middendorf, Identification of forming limits for unidirectional carbon textiles in reality and mesoscopic simulation, KEM 554-557 (2013)
423-432.

[99] P. Hallander, M. Akermo, C. Mattei, M. Petersson, T. Nyman, An experimental study of mechanisms behind wrinkle development during forming of composite laminates, Compos. Part A Appl. Sci. Manuf. 50 (2013) 54-64.

[100] C. Demaría, E. Ruiz, F. Trochu, In-plane anisotropic permeability characterization of deformed woven fabrics by unidirectional injection. Part I: experimental results, Polym. Compos. 28 (6) (2007) 797-811.

[101] C. Demaría, E. Ruiz, F. Trochu, In-plane anisotropic permeability characterization of deformed woven fabrics by unidirectional injection. Part II: prediction model and numerical simulations, Polym. Compos. 28 (6) (2007) 812-827.

[102] M. Louis, U. Huber, Investigation of shearing effects on the permeability of woven fabrics and implementation into LCM simulation, Compos. Sci. Technol. 63 (14) (2003) 2081-2088.

[103] S. Bickerton, E. Sozer, P. Graham, S. Advani, Fabric structure and mold curvature effects on preform permeability and mold filling in the RTM process. Part I. Experiments, Compos. Part A Appl. Sci. Manuf. 31 (5) (2000) 423-438.

[104] D. Magagnato, F. Henning, RTM molding simulation for unidirectional fiber reinforced composite components considering local fiber orientation and fiber volume fraction, J. Plast. Technol. 12 (3) (2016) 135-156.

[105] R.S. Parnas, K.M. Flynn, M.E. Dal-Favero, A permeability database for composites manufacturing, Polym. Compos. 18 (5) (1997) 623-633.

[106] C. Brauner, S. Bauer, A.S. Herrmann, Analysing process-induced deformation and stresses using a simulated manufacturing process for composite multispar flaps, J. Compos. Mater. 49 (4) (2015) 387-402.

[107] P. Steinle, Toleranzmanagement für Bauteile aus kohlenstofffaserverstärktem Kunststoff - Ursachen der geometrischen Streuung, präventive Vorhersagen der Maßhaltigkeit und der Einsatz des Werkstoffes im Rohbau, PhD Thesis (in German) (2015) Karlsruhe, Germany.

[108] T.S. Mesogitis, A.A. Skordos, A.C. Long, Uncertainty in the manufacturing of fibrous thermosetting composites: a review, Compos. Part A Appl. Sci. Manuf. 57 (2014) 67-75.

[109] F. Heieck, F. Hermann, P. Middendorf, K. Schladitz, Influence of the cover factor of 2D biaxial and triaxial braided carbon composites on their in-plane mechanical properties, Compos. Struct. 163 (2017) 114-122.

[110] J. Fuhr, N. Feindler, P. Middendorf, Virtual analysis of draping effects on stiffnes and strength of ply-based composite structures, Proceedings NAFEMS Seminar Simulation, Leipzig, 2014, pp. 266-273.

[111] M.R. Piggott, The effect of fibre waviness on the mechanical properties of unidirectional fibre composites: a review, Compos. Sci. Technol. 53 (2) (1995) 201-205.

[112] H.M. Hsiao, I.M. Daniel, Effect of fiber waviness on stiffness and strength reduction of unidirectional composites under compressive loading, Compos. Sci. Technol. 56 (5) (1996) 581-593.

[113] G. Ernst, M. Vogler, C. Hühne, R. Rolfes, Multiscale progressive failure analysis of textile composites, Compos. Sci. Technol. 70 (1) (2010) 61-72.

[114] A. Altmann, R. Taubert, U. Mandel, R. Hinterhoelzl, K. Drechsler, A continuum damage model to predict the influence of ply waviness on stiffness and strength in ultra-thick unidirectional fiber-reinforced plastics, J. Compos. Mater. 50 (20) (2015) 2739-2755.

[115] G. Karami, M. Garnich, Micromechanical study of thermoelastic behavior of composites with periodic fiber waviness, Compos. Part B Eng. 36 (3) (2005) 241-248.

[116] P.P. Camanho, A. Arteiro, A.R. Melro, G. Catalanotti, M. Vogler, Three-dimensional invariant-based failure criteria for fibre-reinforced composites, Int. J. Solid Struct. 55 (2015) 92-107.

[117] L. Zhao, Y. Li, J. Zhang, L. Zhou, N. Hu, A novel material degradation model for unidirectional CFRP composites, Compos. Part B Eng. 135 (2018) 84-94.

[118] N.K. Naik, R.S. Kumar, Compressive strength of unidirectional composites: evaluation and comparison of prediction models, Compos. Struct. 46 (3) (1999) 299-308.

[119] S.L. Lemanski, M. Sutcliffe, Compressive failure of finite size unidirectional com posite laminates with a region of fibre waviness, Compos. Part A Appl. Sci. Manuf. 43 (3) (2012) 435-444.

[120] D. Scrimieri, S.M. Afazov, A.A. Becker, S.M. Ratchev, Fast mapping of finite element field variables between meshes with different densities and element types, Adv. Eng. Software 67 (2014) 90-98.

[121] National Research Council (U.S.), Integrated Computational Materials Engineering: a Transformational Discipline for Improved Competitiveness and National Security, National Academies Press, Washington, 2008.

[122] G.J. Schmitz, B. Böttger, M. Apel, Microstructural modelling in ICME settings, Proceedings 3rd World Congress on Integrated Computational Materials Engineering (ICME 2015), Springer, 2015.

[123] D. Scrimieri, S.M. Afazov, S.M. Ratchev, An in-core grid index for transferring finite element data across dissimilar meshes, Adv. Eng. Software 88 (2015) 53-62.

[124] A. Bucher, A. Meyer, U.-J. Görke, R. Kreißig, A comparison of mapping algorithms for hierarchical adaptive FEM in finite elasto-plasticity, Comput. Mech. 39 (4) (2007) 521-536.

[125] S. Arya, D.M. Mount, N.S. Netanyahu, R. Silverman, A.Y. Wu, An optimal algorithm for approximate nearest neighbor searching fixed dimensions, J. ACM 45 (6) (1998) 891-923.

[126] S. Chen, L.T. Harper, A. Endruweit, N.A. Warrior, Formability optimisation of fabric preforms by controlling material draw-in through in-plane constraints, Compos. Part A Appl. Sci. Manuf. 76 (2015) 10-19.

[127] D. Dörr, L. Lipowski, L. Kärger, F. Henning, An iterative approach for the determination of tailored blanks for waste-free composite forming by means of $\mathrm{FE}$ forming simulation, IJAutoC 3 (2-4) (2017) 323-338. 
[128] H. Lessard, G. Lebrun, A. Benkaddour, X.-T. Pham, Influence of process parameters on the thermostamping of a [0/90]12 carbon/polyether ether ketone laminate, Compos. Part A Appl. Sci. Manuf. 70 (2015) 59-68.

[129] B.J. Henz, R.V. Mohan, D.R. Shires, A hybrid global-local approach for optimization of injection gate locations in liquid composite molding process simulations, Compos. Part A Appl. Sci. Manuf. 38 (8) (2007) 1932-1946.

[130] F. Trochu, E. Ruiz, V. Achim, S. Soukane, Advanced numerical simulation of liquid composite molding for process analysis and optimization, Compos. Part A Appl. Sci. Manuf. 37 (6) (2006) 890-902.

[131] G. Struzziero, A.A. Skordos, Multi-objective optimisation of the cure of thick components, Compos. Part A Appl. Sci. Manuf. 93 (2017) 126-136.

[132] F.O. Sonmez, M. Akbulut, Process optimization of tape placement for thermoplastic composites, Compos. Part A Appl. Sci. Manuf. 38 (9) (2007) 2013-2023.

[133] B. Wucher, F. Lani, T. Pardoen, C. Bailly, P. Martiny, Tooling geometry optimization for compensation of cure-induced distortions of a curved carbon/epoxy Cspar, Compos. Part A Appl. Sci. Manuf. (2014) 27-35.

[134] C. Acquah, I. Datskov, A. Mawardi, F. Zhang, L.E. Achenie, R. Pitchumani, et al., Optimization under uncertainty of a composite fabrication process using a deterministic one-stage approach, Comput. Chem. Eng. 30 (6-7) (2006) 947-960.

[135] C. Nardari, B. Ferret, D. Gay, Simultaneous engineering in design and manufacture using the RTM process, Compos. Part A Appl. Sci. Manuf. 33 (2) (2002) 191-196.

[136] S. Zein, V. Madhavan, D. Dumas, L. Ravier, I. Yague, From stacking sequences to ply layouts: an algorithm to design manufacturable composite structures, Compos. Struct. 141 (2016) 32-38.

[137] G. Allaire, G. Delgado, Stacking sequence and shape optimization of laminated composite plates via a level-set method, J. Mech. Phys. Solid. 97 (2016) 168-196.

[138] S.N. Sørensen, E. Lund, Topology and thickness optimization of laminated composites including manufacturing constraints, Struct. Multidiscip. Optim. 48 (2) (2013) 249-265.

[139] X.B. Hu, X.Y. Cui, Z.M. Liang, G.Y. Li, The performance prediction and optimization of the fiber-reinforced composite structure with uncertain parameters, Compos. Struct. 164 (2017) 207-218.

[140] M. Poorzeinolabedin, L. Parnas, S.H. Dashatan, Resin infusion under flexible tooling process and structural design optimization of the complex composite part, Mater. Des. 64 (2014) 450-455.

[141] M. Kaufmann, D. Zenkert, M. Åkermo, Cost/weight optimization of composite prepreg structures for best draping strategy, Compos. Part A Appl. Sci. Manuf. 41 (4) (2010) 464-472.

[142] M. Bulla, E. Beauchense, F. Ehrhart, V. Trickov, A holistic simulation driven composite design process, Proceedings NAFEMS Seminar Simulation, Leipzig, 2014, pp. 199-212.

[143] R. Le Riche, A. Saouab, J. Bréard, Coupled compression RTM and composite layup optimization, Compos. Sci. Technol. 63 (15) (2003) 2277-2287.

[144] C.H. Park, W.I. Lee, W.S. Han, A. Vautrin, Simultaneous optimization of composite structures considering mechanical performance and manufacturing cost, Compos. Struct. 65 (1) (2004) 117-127.

[145] W. Hufenbach, M. Gude, Analysis and optimisation of multistable composites under residual stresses, Compos. Struct. 55 (3) (2002) 319-327.

[146] L. Kärger, S. Galkin, D. Dörr, F.J. Schirmaier, A. Oeckerath, K. Wolf, et al., Continuous CAE chain for composite design, established on an HPC system and accessible via web-based user-interfaces, Proceedings NAFEMS World Congress 2017, Stockholm, 2017

[147] D. Nielsen, R. Pitchumani, Intelligent model-based control of preform permeation in liquid composite molding processes, with online optimization, Compos. Part A Appl. Sci. Manuf. 32 (12) (2001) 1789-1803.

[148] P. Carlone, D. Aleksendrić, V. Ćirović, G.S. Palazzo, Meta-modeling of the curing process of thermoset matrix composites by means of a FEM-ANN approach, Compos. Part B Eng. 67 (2014) 441-448.

[149] C. Zimmerling, D. Dörr, F. Henning, L. Kärger, A meta-model based approach for rapid formability estimation of continuous fibre reinforced components, Proceedings 21st ESAFORM Conference, Palermo, 2018, p. 20042.

[150] C. Zimmerling, J. Pfrommer, J. Liu, J. Beyerer, F. Henning, L. Kärger, Application and evaluation of meta-model assisted optimisation strategies for gripper assisted fabric draping in composite manufacturing, Proceedings of ECCM18 - European Conference on Composite Materials, Athens, 2018.

[151] D. Dörr, F.J. Schirmaier, F. Henning, L. Kärger, On the relevance of modeling viscoelastic bending behavior in finite element forming simulation of continuously fiber reinforced thermoplastics, Proceedings 20th ESAFORM Conference, Dublin, 2017, p. 30003.

[152] J. Cao, R. Akkerman, P. Boisse, J. Chen, H.S. Cheng, EF de Graaf, et al., Characterization of mechanical behavior of woven fabrics: experimental methods and benchmark results, Compos. Part A Appl. Sci. Manuf. 39 (6) (2008) 1037-1053.

[153] P. Harrison, M.J. Clifford, A.C. Long, Shear characterisation of viscous woven textile composites: a comparison between picture frame and bias extension experiments, Compos. Sci. Technol. 64 (10-11) (2004) 1453-1465.

[154] B. Zhu, T.X. Yu, X.M. Tao, Large deformation and slippage mechanism of plain woven composite in bias extension, Compos. Part A Appl. Sci. Manuf. 38 (8) (2007) 1821-1828.

[155] S. Bel, P. Boisse, F. Dumont, Analyses of the deformation mechanisms of noncrimp fabric composite reinforcements during preforming, Appl. Compos. Mater. 19 (3) (2012) 513-528.

[156] C. Poppe, D. Dörr, F. Henning, L. Kärger, Experimental and numerical investigation of the shear behaviour of infiltrated woven fabrics, Compos. Part A Appl. Sci. Manuf. (2018) (revision submitted).

[157] F.J. Schirmaier, K.A. Weidenmann, L. Kärger, F. Henning, Characterisation of the draping behaviour of unidirectional non-crimp fabrics (UD-NCF), Compos. Part A Appl. Sci. Manuf. 80 (2016) 28-38.

[158] F. Härtel, P. Harrison, Evaluation of normalisation methods for uniaxial bias extension tests on engineering fabrics, Compos. Part A Appl. Sci. Manuf. 67 (0) (2014) 61-69.

[159] F. Härtel, P. Böhler, P. Middendorf, An integral mesoscopic material characterization approach, KEM 611-612 (2014) 280-291.

[160] F.J. Schirmaier, D. Dörr, F. Henning, L. Kärger, A macroscopic approach to simulate the forming behaviour of stitched unidirectional non-crimp fabrics (UDNCF), Compos. Part A Appl. Sci. Manuf. 102 (2017) 322-335.

[161] S.P. Haanappel, R. Akkerman, Shear characterisation of uni-directional fibre reinforced thermoplastic melts by means of torsion, Compos. Part A Appl. Sci. Manuf. 56 (2014) 8-26.

[162] D. Dörr, F. Henning, L. Kärger, Nonlinear hyperviscoelastic modelling of intra-ply deformation behaviour in Finite element forming simulation of continuously fibrereinforced thermoplastics, Compos. Part A Appl. Sci. Manuf. (109) (2018) 585-596.

[163] A. Margossian, S. Bel, R. Hinterhoelzl, Bending characterisation of a molten unidirectional carbon fibre reinforced thermoplastic composite using a Dynamic Mechanical Analysis system, Compos. Part A Appl. Sci. Manuf. 77 (2015) 154-163.

[164] American Society for Testing and Material, Philadelphia, Standard Test Method for Stiffness of Fabrics (D1388-D1396(2002)), (2002).

[165] ISO/TC 61/SC 13, Composites and Reinforcement Fibres. Textile Glass - Woven Fabrics - Determination of Conventional Flexural Stiffness - Fixed Angle Flexometer method;59.100.10 Textile Glass Materials(4604:2011), (2011).

[166] F.T. Peirce, The "handle" of cloth as measurable quantity, J. Textile Inst. Trans. 21:9 (1930) 377-416.

[167] B. Liang, P. Chaudet, P. Boisse, Curvature determination in the bending test of continuous fibre reinforcements, Strain 53 (1) (2017) e12213.

[168] B. Liang, N. Hamila, M. Peillon, P. Boisse, Analysis of thermoplastic prepreg bending stiffness during manufacturing and of its influence on wrinkling simulations, Compos. Part A Appl. Sci. Manuf. 67 (2014) 111-122.

[169] E de Bilbao, D. Soulat, G. Hivet, A. Gasser, Experimental study of bending behaviour of reinforcements, Exp. Mech. 50 (3) (2010) 333-351.

[170] S. Kawabata, The Standardization and Analysis of Hand Evaluation, second ed. The Textile Machinery Society Japan, 1980.

[171] U. Sachs, R. Akkerman, Viscoelastic bending model for continuous fiber-reinforced thermoplastic composites in melt, Compos. Part A Appl. Sci. Manuf. 100 (2017) 333-341.

[172] P. Boisse, J. Colmars, N. Hamila, N. Naouar, Q. Steer, Bending and wrinkling of composite fiber preforms and prepregs. A review and new developments in the draping simulations, Compos. Part B Eng. 141 (2018) 234-249.

[173] H. Alshahrani, M. Hojjati, Bending behavior of multilayered textile composite prepregs: experiment and finite element modeling, Mater. Des. 124 (2017) 211-224.

[174] D. Soteropoulos, K. Fetfatsidis, J.A. Sherwood, J. Langworthy, Digital method of analyzing the bending stiffness of non-crimp fabrics, Proceedings 14th ESAFORM Conference, Belfast, 2011.

[175] U. Sachs, R. Akkerman, K. Fetfatsidis, E. Vidal-Sallé, J. Schumacher, G. Ziegmann, et al., Characterization of the dynamic friction of woven fabrics: experimental methods and benchmark results, Compos. Part A Appl. Sci. Manuf. 67 (2014) 289-298.

[176] D. Dörr, M. Faisst, T. Joppich, C. Poppe, F. Henning, L. Kärger, Modelling approach for anisotropic inter-ply slippage in finite element forming simulation of thermoplastic UD-Tapes, AIP Conference Proceedings, 1960, p. 20005.

[177] A.M. Murtagh, J.J. Lennon, P.J. Mallon, Surface friction effects related to pressforming of continuous fibre thermoplastic composites, Compos. Manuf. 6 (3-4) (1995) 169-175.

[178] S.R. Morris, C.T. Sun, An investigation of interply slip behaviour in AS4/PEEK at forming temperatures, Compos. Manuf. 5 (4) (1994) 217-224.

[179] M. Åkermo, Y.R. Larberg, J. Sjölander, P. Hallander, Influence of interply friction on the forming of stacked UD prepreg, Proceedings of the 19th International Conference on Composite Materials, 2013, pp. 919-928.

[180] S. Allaoui, G. Hivet, A. Wendling, P. Ouagne, D. Soulat, Influence of the dry woven fabrics meso-structure on fabric/fabric contact behavior, J. Compos. Mater. 46 (6) (2012) 627-639.

[181] C. Mack, H.M. Taylor, 39-the fitting of woven cloth to surfaces, J. Textile Inst. Trans. 47 (9) (1956) T477-T488.

[182] B.P. van West, S.C. Luby, Fabric draping simulation in composites manufacturing part I: description and applications, J. Adv. Mater. (3) (1997) 29-35.

[183] B.P. van West, S.C. Luby, Fabric draping simulation in composites manufacturing part II: analytical methods, J. Adv. Mater. (3) (1997) 36-41.

[184] F.L. Heisey, K.D. Haller, Fitting woven fabric to surfaces in three dimensions, J. Textil. Inst. 79 (2) (1988) 250-263.

[185] F. van der Weeën, Algorithms for draping fabrics on doubly-curved surfaces, Int. J. Numer. Methods Eng. 31 (7) (1991) 1415-1426.

[186] S.G. Hancock, K.D. Potter, Inverse drape modelling-an investigation of the set of shapes that can be formed from continuous aligned woven fibre reinforcements, Compos. Part A Appl. Sci. Manuf. 36 (7) (2005) 947-953.

[187] K. Vanclooster, S.V. Lomov, I. Verpoest, Experimental validation of forming simulations of fabric reinforced polymers using an unsymmetrical mould configuration, Compos. Part A Appl. Sci. Manuf. 40 (4) (2009) 530-539.

[188] J. Sirtautas, A.K. Pickett, P. Lépicier, A mesoscopic model for coupled drape-infusion simulation of biaxial non-crimp fabric, Compos. Part B Eng. 47 (2013) 48-57. 
[189] G. Creech, A. Pickett, Meso-modelling of Non-Crimp Fabric composites for coupled drape and failure analysis, J. Mater. Sci. 41 (20) (2006) 6725-6736.

[190] P. Boisse, H. Hamila, P. Wang, S. Gatouillat, S. Bel, A. Charmetant, Composite reinforcement forming simulation: continous and mesoscopic approaches, Proceedings ICCM18 - 18th International Conference on Composite Materials, Jeju Island, Korea, 2011

[191] B. Hagège, P. Boisse, J.-L. Billoët, Finite element analyses of knitted composite reinforcement at large strain, Revue Européenne des Éléments 14 (6-7) (2005) 767-776.

[192] H. Lin, A.C. Long, M. Sherburn, M.J. Clifford, Modelling of mechanical behaviour for woven fabrics under combined loading, Int. J. Mater. Form. 1 (1) (2008) 899-902.

[193] P. Badel, S. Gauthier, E. Vidal-Sallé, P. Boisse, Rate constitutive equations fo computational analyses of textile composite reinforcement mechanical behaviour during forming, Compos. Part A Appl. Sci. Manuf. 40 (8) (2009) 997-1007.

[194] A. Charmetant, E. Vidal-Sallé, P. Boisse, Hyperelastic modelling for mesoscopic analyses of composite reinforcements, Compos. Sci. Technol. 71 (14) (2011) 1623-1631.

[195] M. Duhovic, P. Mitschang, D. Bhattacharyya, Modelling approach for the prediction of stitch influence during woven fabric draping, Compos. Part A Appl. Sci. Manuf. 42 (8) (2011) 968-978.

[196] L.M. Dangora, C.J. Mitchell, J. Sherwood, J.C. Parker, Deep-Drawing forming trials on a cross-ply thermoplastic lamina for helmet preform manufacture, J. Manuf. Sci. Eng. 139 (3) (2017) 31009.

[197] S.P. Haanappel, R ten Thije, U. Sachs, B. Rietman, R. Akkerman, Formability analyses of uni-directional and textile reinforced thermoplastics, Compos. Part A Appl. Sci. Manuf. 56 (2014) 80-92.

[198] A.K. Pickett, T. Queckborner, P. Deluca, E. Haug, An explicit finite-element solution for the forming prediction of continuous fiber-reinforced thermoplastic sheets, Compos. Manuf. 6 (3-4) (1995) 237-243.

[199] A.K. Pickett, G. Creech, P de Luca, Simplified and advanced simulation methods for prediction of fabric draping, Rev. Eur. Des. Eléments Finis 14 (6-7) (2005) 677-691.

[200] Y. Aimène, E. Vidal-Sallé, B. Hagège, F. Sidoroff, P. Boisse, A hyperelastic approach for composite reinforcement large deformation analysis, J. Compos. Mater. 44 (1) (2010) 5-26.

[201] L. Meunier, G. Chagnon, D. Favier, L. Orgéas, Anisotropic large deformation of geometrically architectured unfilled silicone membranes, Eur. J. Mech. A Solid. 50 (2015) 87-99.

[202] R ten Thije, R. Akkerman, A multi-layer triangular membrane finite element for the forming simulation of laminated composites, Compos. Part A Appl. Sci. Manuf. 40 (6-7) (2009) 739-753.

[203] D. Dörr, F.J. Schirmaier, F. Henning, L. Kärger, A viscoelastic approach for modeling bending behavior in finite element forming simulation of continuously fiber reinforced composites, Compos. Part A Appl. Sci. Manuf. 94 (2017) 113-123.

[204] J. Sjölander, P. Hallander, M. Åkermo, Forming induced wrinkling of composite laminates: a numerical study on wrinkling mechanisms, Compos. Part A Appl. Sci. Manuf. 81 (2016) 41-51.

[205] B. Liang, J. Colmars, P. Boisse, A shell formulation for fibrous reinforcement forming simulations, Compos. Part A Appl. Sci. Manuf. 100 (2017) 81-96.

[206] D. Dörr, T. Joppich, F. Henning, L. Kärger, A coupled thermomechanical approach for finite element forming simulation of continuously fiber-reinforced semi-crystalline thermoplastics, Compos. Part A Appl. Sci. Manuf. 109 (June 2018) 585-596.

[207] M. Machado, L. Murenu, M. Fischlschweiger, Z. Major, Analysis of the thermomechanical shear behaviour of woven-reinforced thermoplastic-matrix composites during forming, Compos. Part A Appl. Sci. Manuf. 86 (2016) 39-48.

[208] E. Guzman-Maldonado, N. Hamila, N. Naouar, G. Moulin, P. Boisse, Simulation of thermoplastic prepreg thermoforming based on a visco-hyperelastic model and a thermal homogenization, Mater. Des. 93 (2016) 431-442.

[209] Y. Denis, E. Guzman-Maldonado, N. Hamila, J. Colmars, F. Morestin, A dissipative constitutive model for woven composite fabric under large strain, Compos. Part A Appl. Sci. Manuf. 105 (2018) 165-179.

[210] X. Peng, Z. Guo, T. Du, W.-R. Yu, A simple anisotropic hyperelastic constitutive model for textile fabrics with application to forming simulation, Compos. Part B Eng. 52 (2013) 275-281.

[211] M.A. Khan, T. Mabrouki, E. Vidal-Sallé, P. Boisse, Numerical and experimenta analyses of woven composite reinforcement forming using a hypoelastic behaviour. Application to the double dome benchmark, J. Mater. Process. Technol. 210 (2) (2010) 378-388.

[212] W. Zhang, H. Ren, B. Liang, D. Zeng, X. Su, J. Dahl, et al., A non-orthogonal material model of woven composites in the preforming process, CIRP Ann. 66 (1) (2017) 257-260.

[213] A. Madeo, G. Barbagallo, M.V. D'Agostino, P. Boisse, Continuum and discrete models for unbalanced woven fabrics, Int. J. Solid Struct. 94-95 (2016) 263-284.

[214] A. Mallach, F. Härtel, F. Heieck, J.-P. Fuhr, P. Middendorf, M. Gude, Experimental comparison of a macroscopic draping simulation for dry non-crimp fabric preforming on a complex geometry by means of optical measurement, J. Compos. Mater. 51 (16) (2016) 2363-2375.

[215] S. Chen, O. McGregor, L.T. Harper, A. Endruweit, N.A. Warrior, Defect formation during preforming of a bi-axial non-crimp fabric with a pillar stitch pattern, Compos. Part A Appl. Sci. Manuf. 91 (2016) 156-167.

[216] V.N. Khiêm, H. Krieger, M. Itskov, T. Gries, S.E. Stapleton, An averaging based hyperelastic modeling and experimental analysis of non-crimp fabrics, Int. J. Solid Struct. 154 (2016) 43-54.

[217] N. Hamila, P. Boisse, S. Chatel, Semi-discrete shell finite elements for textile composite forming simulation, Int. J. Mater. Form. 2 (1) (2009) 169-172.

[218] S. Bel, N. Hamila, P. Boisse, F. Dumont, Finite element model for NCF composite reinforcement preforming: importance of inter-ply sliding, Compos. Part A Appl. Sci. Manuf. 43 (12) (2012) 2269-2277.

[219] M.V. d'Agostino, I. Giorgio, L. Greco, A. Madeo, P. Boisse, Continuum and discrete models for structures including (quasi-) inextensible elasticae with a view to the design and modeling of composite reinforcements, Int. J. Solid Struct. 59 (2015) $1-17$.

[220] G. Barbagallo, A. Madeo, I. Azehaf, I. Giorgio, F. Morestin, P. Boisse, Bias extension test on an unbalanced woven composite reinforcement: experiments and modeling via a second-gradient continuum approach, J. Compos. Mater. 51 (2) (2016) 153-170.

[221] X.-T. Pham, F. Trochu, Simulation of compression resin transfer molding to manufacture thin composite shells, Polym. Compos. 20 (3) (1999) 436-459.

[222] N. Kuentzer, P. Simacek, S.G. Advani, S. Walsh, Permeability characterization of dual scale fibrous porous media, Compos. Part A Appl. Sci. Manuf. 37 (11) (2006) 2057-2068.

[223] D. Magagnato, B. Thoma, F. Henning, Experimental characterization to determine the influence of different binder systems on the preform permeability during RTM manufacturing, J. Plast. Technol. 11 (4) (2015) 256-270.

[224] M.V. Bruschke, S.G. Advani, A finite element/control volume approach to mold filling in anisotropic porous media, Polym. Compos. 11 (6) (1990) 398-405.

[225] C.A. Fracchia, J. Castro, C.L. Tucker III, A finite element/control volume simulation of resin transfer mold filling, Proceedings of the American Society for Composites, 4th Technical Conference, 1989, pp. 157-166.

[226] F. Trochu, R. Gauvin, D.-M. Gao, Numerical analysis of the resin transfer molding process by the finite element method, Adv. Polym. Technol. 12 (4) (1993) 329-342.

[227] D. Magagnato, M. Frey, A. Bernath, P. Steibler, F. Henning, Experimentelle und numerische Untersuchung der Infiltration bei der RTM-Fertigung, in: A. Wanner, K. Weidenmann (Eds.), Verbundwerkstoffe und Werkstoffverbunde, 2013, pp. 511-517.

[228] B.R. Gebart, Permeability of unidirectional reinforcements for RTM, J. Compos. Mater. (26) (1992) 1100-1133.

[229] P.B. Nedanov, S.G. Advani, Numerical computation of the fiber preform permeability tensor by the homogenization method, Polym. Compos. 23 (5) (2002) 758-770.

[230] K. Yazdchi, S. Srivastava, S. Luding, Micro-macro relations for flow through random arrays of cylinders, Compos. Part A Appl. Sci. Manuf. 43 (11) (2012) 2007-2020.

[231] M.V. Bruschke, Flow of generalized Newtonian fluids across a periodic array of cylinders, J. Rheol. 37 (3) (1993) 479

[232] M.A. Choi, M.H. Lee, J. Chang, S.J. Lee, Permeability modeling of fibrous media in composite processing, J. Non Newton. Fluid Mech. 79 (2-3) (1998) 585-598.

[233] R. Arbter, J.M. Beraud, C. Binetruy, L. Bizet, J. Bréard, S. Comas-Cardona, et al., Experimental determination of the permeability of textiles: a benchmark exercise, Compos. Part A Appl. Sci. Manuf. 42 (9) (2011) 1157-1168.

[234] N. Vernet, E. Ruiz, S. Advani, J.B. Alms, M. Aubert, M. Barburski, et al., Experimental determination of the permeability of engineering textiles: benchmark II, Compos. Part A Appl. Sci. Manuf. 61 (2014) 172-184.

[235] S. Bickerton, E.M. Sozer, P. Šimácek, S.G. Advani, Fabric structure and mold curvature effects on preform permeability and mold filling in the RTM process. Part II. Predictions and comparisons with experiments, Compos. Part A Appl. Sci. Manuf. 31 (5) (2000) 439-458.

[236] J. Seuffert, L. Kärger, F. Henning, Simulating mold filling in compression resin transfer molding (CRTM) using a three-dimensional finite-volume formulation, J. Compos. Sci. 2 (2) (2018) 23.

[237] A. Dereims, S. Drapier, J.-M. Bergheau, P de Luca, 3D robust iterative coupling of Stokes, Darcy and solid mechanics for low permeability media undergoing finite strains, Finite Elem. Anal. Des. 94 (2015) 1-15.

[238] A. Abbassi, M. Shahnazari, Numerical modeling of mold filling and curing in nonisothermal RTM process, Appl. Therm. Eng. 24 (16) (2004) 2453-2465.

[239] R.B. Dessenberger, C.L. Tucker, Thermal dispersion in resin transfer molding, Polym. Compos. 16 (6) (1995) 495-506.

[240] C. Binetruy, S.G. Advani, Foam core deformation during liquid molding of sandwich structures: modeling and experimental analysis, J. Sandw. Struct. Mater. 5 (4) (2003) 351-375.

[241] M. Deleglise, C. Binetruy, P. Krawczak, Simulation of LCM processes involving induced or forced deformations, Compos. Part A Appl. Sci. Manuf. 37 (6) (2006) 874-880.

[242] F. Shi, X. Dong, 3D numerical simulation of filling and curing processes in nonisothermal RTM process cycle, Finite Elem. Anal. Des. 47 (7) (2011) 764-770.

[243] L.J. Lee, W.B. Young, R.J. Lin, Mold filling and cure modeling of RTM and SRIM processes, Compos. Struct. 27 (1994) 109-120.

[244] P. Rosenberg, B. Thoma, F. Henning, Investigation of a New Cavity Pressure Controlled HP-RTM Process Variant (PC-RTM), SPE Automotive Divison, 2017.

[245] J. Seuffert, P. Rosenberg, L. Kärger, F. Henning, M. Kothmann, G. Deinzer, Mold filling simulation of a pressure controlled resin transfer molding (PC-RTM) process - method and application, The 14th International Conference on Flow Processing in Composite Materials (FPCM-14), 2018.

[246] G. Fernlund, A. Osooly, A. Poursartip, R. Vaziri, R. Courdji, K. Nelson, et al., Finite element based prediction of process-induced deformation of autoclaved composite structures using 2D process analysis and 3D structural analysis, Compos. Struct. 62 (2) (2003) 223-234

[247] P.P. Parlevliet, H.E. Bersee, A. Beukers, Residual stresses in thermoplastic composites-a study of the literature-Part I: formation of residual stresses, Compos. 
Part A Appl. Sci. Manuf. 37 (11) (2006) 1847-1857.

[248] L.P. Canal, M. Benavente, M. Hausmann, V. Michaud, Process-induced strains in RTM processing of polyurethane/carbon composites, Compos. Part A Appl. Sci. Manuf. 78 (2015) 264-273.

[249] S.R. White, H.T. Hahn, Process modeling of composite materials: residual stress development during cure. Part II. Experimental validation, J. Compos. Mater. 26 (16) (1992) 2423-2453.

[250] D.J. O'Brien, P.T. Mather, S.R. White, Viscoelastic properties of an epoxy resin during cure, J. Compos. Mater. 35 (10) (2001) 883-904.

[251] Y.K. Kim, S.R. White, Stress relaxation behavior of 3501-6 epoxy resin during cure, Polym. Eng. Sci. 36 (23) (1996) 2852-2862.

[252] K.J. Yoon, J.-S. Kim, Effect of thermal deformation and chemical shrinkage on the process induced distortion of carbon/epoxy curved laminates, J. Compos. Mater. 35 (3) (2001) 253-263.

[253] S.L. Agius, M. Joosten, B. Trippit, C.H. Wang, T. Hilditch, Rapidly cured epoxy/ anhydride composites: effect of residual stress on laminate shear strength, Compos. Part A Appl. Sci. Manuf. 90 (2016) 125-136.

[254] L.K. Jain, Y.-W. Mai, Stresses and deformations induced during manufacturing. Part I: theoretical analysis of composite cylinders and shells, J. Compos. Mater. 31 (7) (1997) 672-695.

[255] S.R. White, Y. Kim, Process-induced residual stress analysis of AS4/3501-6 composite material, Mech. Compos. Mater. Struct. 5 (2) (1998) 153-186.

[256] G. Hu, J.E. Luan, S. Chew, Characterization of chemical cure shrinkage of epoxy molding compound with application to warpage analysis, J. Electron. Packag. Trans. ASME 131 (1) (2009) 1-6.

[257] J. Svanberg, J. Holmberg, Prediction of shape distortions. Part II. Experimental validation and analysis of boundary conditions, Compos. Part A Appl. Sci. Manuf. 35 (6) (2004) 723-734.

[258] M.R. Wisnom, M. Gigliotti, N. Ersoy, M. Campbell, K.D. Potter, Mechanisms generating residual stresses and distortion during manufacture of polymer-matrix composite structures, Compos. Part A Appl. Sci. Manuf. 37 (4) (2006) 522-529.

[259] P.P. Parlevliet, H.E. Bersee, A. Beukers, Residual stresses in thermoplastic composites - a study of the literature. Part III: effects of thermal residual stresses, Compos. Part A Appl. Sci. Manuf. 38 (6) (2007) 1581-1596.

[260] C. Albert, G. Fernlund, Spring-in and warpage of angled composite laminates, Compos. Sci. Technol. 62 (14) (2002) 1895-1912.

[261] L.K. Jain, B.G. Lutton, Y.-W. Mai, R. Paton, Stresses and deformations induced during manufacturing. Part II: a study of the spring-in phenomenon, J. Compos. Mater. 31 (7) (1997) 696-719.

[262] D.A. Darrow, L.V. Smith, Isolating components of processing induced warpage in laminated composites, J. Compos. Mater. 36 (21) (2002) 2407-2419.

[263] D.W. Radford, Cure shrinkage induced warpage in flat uni-axial composites, J. Compos. Technol. Res. 15 (4) (1993) 290-296.

[264] D.W. Radford, Volume fraction gradient induced warpage in curved composite plates, Compos. Eng. 5 (7) (1995) 923-934.
[265] E. Kappel, D. Stefaniak, D. Holzhüter, C. Hühne, M. Sinapius, Manufacturing distortions of a CFRP box-structure - a semi-numerical prediction approach, Compos. Part A Appl. Sci. Manuf. (2013) 89-98.

[266] C. Dong, Model development for the formation of resin-rich zones in composites processing, Compos. Part A Appl. Sci. Manuf. 42 (4) (2011) 419-424.

[267] Z.-S. Gao, W.-B. Young, Study of the bending induced gap in fiber preforming of woven fiber mats, Polym. Compos. 23 (2) (2002) 239-248.

[268] D.W. Radford, R.J. Diefendorf, Shape instabilities in composites resulting from laminate anisotropy, J. Reinforc. Plast. Compos. 12 (1) (1993) 58-75.

[269] G. Fernlund, Spring-in of angled sandwich panels, Compos. Sci. Technol. 65 (2) (2005) 317-323.

[270] N. Ersoy, K. Potter, M.R. Wisnom, M.J. Clegg, Development of spring-in angle during cure of a thermosetting composite, Compos. Part A Appl. Sci. Manuf. 36 (12) (2005) 1700-1706.

[271] P. Causse, E. Ruiz, F. Trochu, Spring-in behavior of curved composites manufactured by flexible injection, Compos. Part A Appl. Sci. Manuf. 43 (11) (2012) 1901-1913.

[272] E. Kappel, D. Stefaniak, T. Spröwitz, C. Hühne, A semi-analytical simulation strategy and its application to warpage of autoclave-processed CFRP parts, Compos. Part A Appl. Sci. Manuf. 42 (12) (2011) 1985-1994.

[273] J.T. Tzeng, Predictions and experimental verification of residual stresses in thermoplastic composite cylinders, J. Thermoplast. Compos. Mater. 8 (2) (1995) 163-179.

[274] M.W. Hyer, D.E. Cooper, D. Cohen, Stresses and deformations in cross-ply composite tubes subjected to a uniform temperature change, J. Therm. Stresses 9 (2) (1986) 97-117.

[275] L.P. Kollår, Approximate analysis of the temperature induced stresses and deformations of composite shells, J. Compos. Mater. 28 (5) (1994) 392-414.

[276] P. Sunderland, W. Yu, J.A. Mnson, A thermoviscoelastic analysis of process-induced internal stresses in thermoplastic matrix composites, Polym. Compos. 22 (5) (2001) 579-592.

[277] L. Jun, Y. XueFeng, L. YingHua, C. ZhangZhi, K. ZheJun, H. XiaoCai, et al., Thermo-viscoelastic analysis of the integrated T-shaped composite structures, Compos. Sci. Technol. 70 (10) (2010) 1497-1503.

[278] S. Clifford, N. Jansson, W. Yu, V. Michaud, J.A. Månson, Thermoviscoelastic anisotropic analysis of process induced residual stresses and dimensional stability in real polymer matrix composite components, Compos. Part A Appl. Sci. Manuf. 37 (4) (2006) 538-545.

[279] M. Zarrelli, I.K. Partridge, A. D'Amore, Warpage induced in bi-material specimens: coefficient of thermal expansion, chemical shrinkage and viscoelastic modulus evolution during cure, Compos. Part A Appl. Sci. Manuf. 37 (4) (2006) 565-570.

[280] P.P. Parlevliet, H.E. Bersee, A. Beukers, Residual stresses in thermoplastic composites-a study of the literature-Part II: experimental techniques, Compos. Part A Appl. Sci. Manuf. 38 (3) (2007) 651-665. 


\section{Repository KITopen}

Dies ist ein Postprint/begutachtetes Manuskript.

Empfohlene Zitierung:

Henning, F.; Kärger, L.; Dörr, D.; Schirmaier, F. J.; Seuffert, J.; Bernath, A.

Fast processing and continuous simulation of automotive structural composite components.

2019. Composites science and technology, 171

doi:10554/IR/1000090343

Zitierung der Originalveröffentlichung:

Henning, F.; Kärger, L.; Dörr, D.; Schirmaier, F. J.; Seuffert, J.; Bernath, A.

Fast processing and continuous simulation of automotive structural composite components.

2019. Composites science and technology, 171, 261-279.

doi:10.1016/j.compscitech.2018.12.007 